\title{
CHI Against Bullying
}

\author{
Taking Stock of the Past and Envisioning the Future
}

\author{
Netta Iivari \\ INTERACT Research Unit, University \\ of Oulu, Finland \\ netta.iivari@oulu.fi
}

\author{
Leena Ventä-Olkkonen \\ INTERACT Research Unit, University \\ of Oulu, Finland \\ leena.venta-olkkonen@oulu.fi
}

\author{
Sumita Sharma \\ INTERACT Research Unit, University \\ of Oulu, Finland \\ sumita.sharma@oulu.fi
}

\author{
Tonja Molin-Juustila \\ INTERACT Research Unit, University \\ of Oulu, Finland \\ tonja.molin-juustila@oulu.fi
}

\author{
Essi Kinnunen \\ INTERACT Research Unit, University \\ of Oulu, Finland \\ essi.kinnunen@oulu.fi
}

\begin{abstract}
Bullying is a challenge concerning us all, and particularly our children. This has already been acknowledged by $\mathrm{CHI}$, among others. Despite the interest, there is a lack of comprehensive understanding of the state of the art - a critical review is needed, addressing bullying in the lives of children, in the context of and/or by the means of design and technology, covering $\mathrm{CHI}$ as well as related computing fields, being inspired by the strong body of knowledge within human sciences. We report on a comprehensive literature review on the topic, with the aim to understand what and how has been done so far to handle this troublesome and widespread phenomenon as well as to indicate how to move the field forward. We report how the topic has been examined and with what kind of means tackled, revealing interesting underlying assumptions about design, technology and human agency.
\end{abstract}

\section{CCS CONCEPTS}

- Human-centered computing; • Human computer interaction (HCI) $\rightarrow$ HCI theory, concepts and models;

\section{KEYWORDS}

Bullying, Cyberbullying, Online harassment, Children, Adolescent, Youth, Teenager

\section{ACM Reference Format:}

Netta Iivari, Leena Ventä-Olkkonen, Sumita Sharma, Tonja Molin-Juustila, and Essi Kinnunen. 2021. CHI Against Bullying: Taking Stock of the Past and Envisioning the Future. In CHI Conference on Human Factors in Computing Systems (CHI '21), May 08-13, 2021, Yokohama, Japan. ACM, New York, NY, USA, 17 pages. https://doi.org/10.1145/3411764.3445282

\section{INTRODUCTION}

Bullying is a challenge concerning us all. From toddlers in the kindergarten to adults in the workplace, people gain experiences around bullying as part of their everyday life - as bullies, as those

\section{(c) (i) $\odot$}

This work is licensed under a Creative Commons

Attribution-NonCommercial-NoDerivs International 4.0 License.

CHI '21, May 08-13, 2021, Yokohama, Japan

(C) 2021 Copyright held by the owner/author(s)

ACM ISBN 978-1-4503-8096-6/21/05.

https://doi.org/10.1145/3411764.3445282 being bullied, as by-standers, as enablers or supporters. Bullying is a cultural, group-based and power-laden phenomenon, an unwanted yet an unfortunately common one. The society has reacted strong against it, but it seems to be a challenge to subdue it in our society and culture. Even if the problem is prevalent in the lives of adults and children alike, there is a particular concern to address bullying from the perspective of children and their everyday life: we, adults of today, should be taking action to enable the young generation to grow up and live their future life in a world with less concern due to bulling.

The challenge of bullying has already been acknowledged by the $\mathrm{CHI}$ community as well as by many other research communities. Research within the disciplines of psychology, educational and health sciences and child and youth studies, among others, have generated a huge body of knowledge on the topic, while also various computing fields have generated their contribution. Some of this vast body of research concerns adults and bullying at the workplace, while most of the literature addresses specifically children and the youth. While surprisingly few studies have so far been published in CHI $[5,38,75,89,91,95]$ there are studies published within related publications forums such as in Interaction Design and Children conference [3, 8, 46, 57, 59, 118, 119, 132, 142]. Despite the evident interest, there is a lack of comprehensive understanding of the state of the art in $\mathrm{CHI}$ - a critical review is needed, addressing bullying in the lives of children, in the context of and/or by the means of design and technology, covering also related computing fields, being inspired by the strong body of knowledge within human sciences. We have conducted a comprehensive literature review on the topic, with the aim to understand what and how CHI has so far done against this troublesome and widespread phenomenon as well as to indicate how to move the field forward. We study how the topic has been examined as well as with what kind of means the phenomenon of bullying has been addressed, revealing underlying assumptions about design, technology and human agency. Overall, the review reveals fascinating themes, topics, tools, distinctions and underlying assumptions characterizing current research as well as plenty of untrodden paths for future work.

The paper is structured as follows. Next section discusses the variety involved with the concept of bullying in the literature and outlines how it will be approached in this study. Section three presents the research methodology of this literature review, while section four outlines its main findings. Section five discusses the 
implications for research and design and section six concludes the paper.

\section{BULLYING AS A CONCEPT}

There are various definitions for bullying. In this literary review, many of the reviewed papers have used Olweus's [108] definitions of bullying either directly or modified those. Olweus [108] defines bullying as a form of aggressive behavior against victims who cannot defend themselves. According to this definition, used by Salmivalli et al. [122] and Johansson et al. [70], among others, bullying is behavior where a child or children deliberately and repeatedly use their more powerful position to cause harm to a peer. Often this happens in the school context which can be specified as school bullying. Casas et al. have used the Olweus's definition as a basis. They see bullying as a psychosocial problem involving intentional and repetitive harming of other people. They also include in their definition the power imbalance between the person being bullied and the bully, which causes negative effects on both sides. [25]

The abuse of power between people or power imbalance is also used in bullying definitions by other authors. Kubiszewski et al. [82] say that bullying is an intentional strategy by students to set up an asymmetrical relationship with another student based on their physical or psychological power. Slee and Mohyla [129] refer to an article by Taki et al. who have argued that bullying behavior is characterized by power imbalance and the intent is to have negative effect on the mental health of the less powerful side of the relationship. In other words, bullying is taking advantage of someone else's disadvantages. Kärnä et al. [83] refer to an article by Smith \& Sharp and state that bullying is systematic abuse of power affecting the lives of numerous people around the world, which makes bullying a world-wide problem.

In addition to power imbalance, the negative effects of bullying are highlighted. Bullying is a form of intentional, unwanted and repeated aggression, which is targeted to hurt another people physically and/or mentally [103, 151]. Bullying means systematically and continuously inflicting physical harm and/or psychological distress on one person or a group of people (according to the National Education Association's definition used by Battey and Ebbeck [9]). A highly used definition of a victim, a person who is being bullied, is also made by Olweus [108], used in articles by Kaufman et al. [73], $\mathrm{Xu}$ [149] and Saracho [124] which defines a bullied or victimized person as a person who is being repeatedly and over time exposed to negative actions by other people.

Research has also recognized that technology is a medium and site for bullying. Given the extensive use of social media and technology for online communication by schoolchildren, bullying has permeated from school playground to cyber spaces (e.g. $[1,7,28,35])$. Similar to physical bullying, cyberbullying is multifaceted and includes posting threatening, hateful, or abusive messages via emails, social media posts, and public or private comments and chats, and hacking into accounts to access personal information and/or blackmailing [35]. Cyberbullying can occur also outside the school day, and impacts the school experience and everyday social life of the cyber-victim [1], A study by Chan et al. [28] with secondary school students and counsellors reveals that bullying moves seamlessly between the students' online and physical worlds, necessitating action against cyberbullying as much as bullying in the physical world. While the prevalence of bullying vs cyberbullying in schools is under research $[28,109]$, cyberbullying is potentially just as harmful if not more.

Additionally to these widely cited definitions of bullying, we have been inspired by solution-focused brief therapy [37] in general and its approach to bullying [155] in particular. Solution-focused therapeutic approach has been widely used in social work practice. It has been described as the strength and future oriented approach providing a humanistic stance for problem solving while focusing on the resources of clients and the social environment they live in. Within the approach, a hopeful future is created as well as an empowering relationship between clients and professionals, i.e. social workers specifically. [51] In addition to psychological problems, solution focused approach is considered as an excellent intervention approach for behavioral and interpersonal issues [75]. According to a recent review, there is specifically strong empirical evidence for the strength-oriented techniques and the effectiveness of the method of "co-construction of meaning" used for building solutions with clients [52]. Important to note is that we do not utilize the solution-focused approach literally; instead, we highlight some core issues as foundation principles in the context of bullying. First, instead of problem-based approach, the approach focuses on social behavior opposite of bullying [155: 287]: instead of decreasing or preventing undesired behavior or talking about bullying, it is suggested to focus on favorable behaviors such as promoting friendships and compassion, respecting each other as well as supporting and helping each other. Positive feedback has been emphasized in solution-focused therapy in general [37]. According to Young [155], the aim is that children are happy. Nobody is judged (as a bully or a victim) due to bullying; instead, everyone is considered capable to find solutions for making the school a happy place for all where everyone is helping others to feel good and to enjoy their stay. All children are also considered potential participants in this process, following the idea of a "support group for the suffering child" [155].

\section{RESEARCH METHODOLOGY}

The literary review was carried out by conducting searches in the ACM Digital Library and Scopus. ACM Digital Library was selected as it includes a number of HCI journals and conferences. However, it also lacks many high-quality HCI journals, due to which SCOPUS was also selected - it includes several respected HCI journals. All the searches were made using different combinations and various modifications of the following keywords: bullying, school bullying, cyberbullying, online bullying, online harassment, school violence, children, youth, adolescent, teenager, student, technology, intervention, program, and prevention. The searches were made with advanced search and the previously mentioned keywords were to be found in the title, abstract or keywords. In SCOPUS, we also limited the results to studies classified as computer science.

The search results were sorted by relevance and the papers were skimmed through. If a paper seemed relevant to the study, it was added into an Excel sheet. The Excel sheet including all the found papers was later analyzed in more detail and if the paper in question did not contain useful information, it was dropped out of this 
literature review. The inclusion criteria for papers was that there should be a mention of children or youth or school and technology should be used to either collect data or to help prevent or mitigate the effects of bullying in some way. We considered children to include all minors. We opted for a broad coverage of studies on children and bullying in the computing context: we considered this offers useful insights and inspiration for further $\mathrm{CHI}$ research. We excluded papers with no mention of technology or computing. This decision was made because bullying as itself has been studied too extensively to cover it all. We had a specific interest in interventions illustrating how we as a community have taken action against bullying. Hence, we focused especially on studies with an intervention reflecting our disciplinary background and orientation, i.e. utilizing design or technology against bullying. In the end, we excluded papers for the following reasons: the papers did not have any relationship to technology or computing, the papers did not address children, the papers did not include any intervention against bullying or the papers did not report on research (e.g. tutorials). In total, 146 relevant papers were included and added to the Excel sheet (76 from computing disciplines/70 from other disciplines, 53 on primary school-aged children, 35 on adolescents $/ 58$ on younger, older or wider age groups, 69 published since 2016/77 published before 2016). The papers are listed in Appendix A, with information on the age groups of children addressed, country of the study, the main methods used for collecting data on bullying and the main focus of solutions proposed for tackling bullying (design or technology). Sometimes a lot of interpretation was needed to identify the main methods for data collection and the main foci in terms of the solutions proposed, as several methods or foci were identifiable, in which case the Appendix identifies the most prominent ones.

Data analysis was done collaboratively and iteratively by the authors. Decision was made first to divide the papers into general categories of interest. The categories that inductively emerged were bullying in general, technology, cyberbullying, methods, and bullying prevention/intervention strategies. Two of the authors carried out the searches and one author the initial categorization, after which the other authors joined in and the authors together brainstormed on how to continue and deepen the analysis. The analysis foci developed in a data driven manner into the following aspects: 1) research methods employed to study bullying and 2) the ways design and technology have been harnessed to address bullying. The authors collaboratively conducted the analysis, which along these lines eventually ended up in focusing on distinct assumptions about human agency, the potential of design and technology; and nature of the interventions introduced around bullying in the literature. These assumptions can be argued of abductively emerging during the analysis process: partly they were still identified in a data driven manner from the paper set, but partly their identification was informed by the broader theoretical framings and backgrounds of the authors. Overall, in the last phase of analysis, we ended up in examining the papers in terms of their assumptions on human beings being 1) lazy, passive, unmotivated to work against bullying, i.e. in need to be monitored, controlled, surveyed, and pushed, or 2) active, motivated to work against bullying, taking responsibility for bullying and being self-motivated for action taking, taking ownership and relying on own initiative. Moreover, we noted whether the interventions emphasized the potential of design or the potential of technology, whether they focused on problems or on positive aspects and strengths, and whether they were individual or collective focused.

\section{FINDINGS}

This section first summarizes the methods relied on in prior research to collect data on bullying, and then explores the roles design and technology have played in prior research tackling bullying. Regarding research methods, surveys dominate in our dataset (54 papers), while interviews and reflection-based/creative hands on methods are less common (13 papers, 14 papers). Technology-based methods (28) are discussed in the following subsection, in which studies tackling bullying through technology (66) and design (16) are discussed.

\subsection{CHI Against Bullying - A Variety Of Research Methods}

4.1.1 Interview/Survey-Based Methods. Questionnaires and surveys are well-used methods for studying bullying within different disciplines (see e.g. [10,11, 19, 23]). Different kinds of survey instruments are in use, while quite often used is the Olweus' bully/victim questionnaire. As for survey research on bullying, for instance, Chen [31] conducted a self-report surveys of perceived severity and frequency of being bullied with 1816 elementary school students in 13 schools in Taiwan and Ciucci et. al. [32] used "How I feel -questionnaire" with 1379 8-12 years old pupils in Italy. Also interviews and focus groups are used for studying the phenomenon. Kubiszewski and her colleagues [82] studied the relationship between cyber bullying and school bullying by interviewing 1459 11-17-year-old adolescents in France. Agatston and colleagues [1] used focus group method with 148 high school students in United States for understanding the effect of cyber bullying. Interviews and focus groups have been utilized also with younger children for studying bullying at kindergarten in Norway [62].

In the HCI field, surveys and interviews are often conducted in addition to other methods. Usually interviews and surveys have been used for taking stock of the current situation to better target the later - often design oriented - activities. For instance, in a study by Rutta et. al. [119] in Italy, teacher interviews helped to identify typical conflict sensitive situations in classroom on which the children concentrated within the following activities. In [5] survey was used to understand how the (9th and 12th grade) participants in a private high school in U.S. interacted with social media and different technologies, and to provide contextual information to connect design sessions with participants' personal experiences. Also focus groups may serve the same purpose. For example, in [5] focus groups were used for familiarizing with the teenaged participants' environment aiming to understand how the participants interacted with social media platforms and how these platforms might be used for cyberbullying.

4.1.2 Reflection Based Methods. Interviews and surveys ask questions from the respondents, but there are also methods reported in the literature that more intentionally aim at arousing reflection on the topic among the participants. Previous HCI literature describes several storytelling and storyboarding methods for studying bullying and discrimination (see e.g. [16, 132, 138]). For example, 
Rutta et. al. [118] describe a pilot study with primary school children using a comic-based digital storytelling system. The system facilitated children to create stories and to reflect on situations involving discrimination at school. Tsai et. al. [138] used Scratch multimedia editing tool so support storytelling through animation with junior high school students in Taiwan. In this experiment, children were acting in roles of bullies or victims. According to Tsai et al. [138] storytelling is a good approach to situate students in specific scenarios for easily providing assessment and guidance for students to resolve conflicts. Hall [57] used a classroom-based approach with 8-11-year-olds in UK and Germany involving use of electronic storyboarding software for generating and evaluating bullying scenarios. The method aimed to capture the stories and experiences that children tell about bullying. These stories included both physical and social exclusion type of bullying.

Drama based methods, e.g. educational drama [94] or theater of the oppressed [[113], are another interesting category of reflective type bullying related studies. Drama, theater and role-playing methods are quite commonly used and recognized in, for instance, health promotion interventions [71]. Through role-playing children are able to put themselves and others into hypothetical situations and adopt different persons' perspectives and thus, they can define themselves through the role and to see the "other" in themselves. [94]. Joronen states that "Drama can be used to give space to articulate and respond to emotions concerning bullying, to model and practice non-violent responses to aggression, to consider the consequences of one's actions, and to empower children to stand up to bullying." [71]

Drama based approaches have been utilized also in bullying studies in HCI. Paracha et. al. [113], included interactive theater-based methods in their participatory design approach for designing and developing a virtual environment with 7-12-year-old children in Japan for moral, social and emotional learning. More specifically they utilized "Theater of the Oppressed" interactive theatre where the audience participates in the drama, taking responsibility for actors on the stage, advising them and contributing to the narrative. The authors used the technique to explore story arcs, character motivations and plot points. Another example of drama-based methods in the literature is virtual role-playing in an antibullying intervention "FearNot!" [45]. In this intervention, 8-11-year-old students acted as spectators to bullying episodes but were drawn into the scene through conversation with the victimized character. The intervention strategy aims to increase the awareness of bystanders in bullying and to take more active role by standing up against the bully and helping the victim. The evaluation of the concept was conducted with children in Germany and UK.

4.1.3 Creative Hands on Methods. HCI literature is also strong in employing more design-oriented methods, including various kinds of hands-on, creative type of methods. Indeed, such creative methods have been used, and for several purposes, in previous $\mathrm{HCI}$ bullying related literature such as for sensitizing with the theme, developing ideas and low-fi prototyping. For instance, in [142] drawing was used as a sensitizing method as 9-10-year-old children were asked to draw a class with bad atmosphere and later to continue by forming a collage of problematic situations in a study conducted in two schools in Belgium. Prototyping and making with crafting materials was used for ideation and developing further the initial ideas [142]. Also in [5] bags of stuff method was used with 9th and 12th graders, accompanied with a scenario description of a cyberbullied teenager, and the participants were asked to create solutions for the bullied teenager's problem. Hall et. al. [57], furthermore, used storyboarding method for 8-11-year-old children to both generate and evaluate scenarios for exploring bullying issues.

\subsection{CHI Against Bullying - Design vs. Technology}

4.2.1 Against Bullying with Technology. The literature is full of evidence of educators, researchers, practitioners and caregivers employing a variety of technology-mediated solutions to prevent, address, and mitigate bullying, both online and offline. This can include low-fi approaches such as trainings and counseling using multimedia content and mobile applications, multimodal solutions, to high-fi immersive solutions such as virtual worlds, real time text analysis in online communication and surveillance and monitoring. While technology mediated interventions are common, increased use of technology and social media has ironically also been a harbinger of bullying and online harassment. Approaches to prevent, address, and mitigate cyberbullying incorporate a combination of monitoring, reporting, and educating interventions and solutions [35]. The different technology-mediated approaches towards (cyber)bullying are discussed next.

E-learning and mobile applications: E-learning programs are possibly the most commonly used methods, with successful outcomes, to raise awareness against bullying through trainings and interventions ([117, 123, 137, 105]). A pilot study of StandUp, an online bullying prevention program, with high school students (ages from 14-18 years) in the USA showed that participants improved their social relationships skills already after three sessions with "reduced odds of perpetrating and experiencing emotional and physical bullying, and of passively standing by as others were bullied" [137]. Mobile applications enable quick reporting of incidents [49] and provide a mechanism to teach online safety [95]. Ferreira et al. [49] reviewed ten mobile applications in the context of bullying at schools by comparing them against eight salient features, from identification and denunciation of school violence, to providing coping strategies, information and online links, and news. Their study revealed that of the ten currently available mobile applications (in for instance Google Play Store), none provide wholly or partially all eight features, highlighting needs for improvements. Sutherland et al. [134] worked with 10-12 years old participants in a primary school in Melbourne, Australia, where they asked them to rate the severity and likelihood of them reporting instances of cyberbullying by showing them animated scenarios. They report that "severity played a greater role in influencing bystander's decisions to report than it did for victims themselves" [134], indicating the crucial role of bystanders even in the case of online harassment. Badillo-Urquiola et al. [8] worked with children in the US aged 8-11 years to co-design anti-cyberbullying features for $\mathrm{Mu}-$ sical.ly/TikTok that focus on children's agency and privacy and provide automated (adult) assistance.

Multimodal and virtual solutions: While online and mobilebased interventions are frequently employed and studied, there is 
a growing interest in exploring novel and interactive technologies for preventing, monitoring, addressing, and trainings both students and teachers against bullying, especially at schools. This includes wearable technology that measures physiological data such as heartrate monitors, in addition to other forms of monitoring, to detect and identify instances of bullying [18, 48], and multisensory based applications to detect bullying $[151,152]$. With the prevalence of virtual reality in the past decade, there is also a keen interest in simulating virtual worlds where participants role-play and enact scenarios or dramas related to bullying $[6,45,58]$. In a study by Stavroulia et al. [133] in Cyprus, teachers aged from 20-45 years were transported into a virtual middle school using head mounted virtual reality glasses where they were presented realistic avatars of students interacting socially. The teachers were tasked to identify alarming behaviors in these interactions and mediate them using gaze-based interaction. While training and education in virtual worlds is a common approach, virtual worlds themselves can be plagued with bullying. Zwaan et al. [Zwaan, 2010] propose virtual buddies that provide peer support for victims of bullying, while Bosse and Stam [15] consider how virtual agents could "minimise the amount of occurrences of cyberbullying in the first place". They employed a system of rewards and punishments to nudge their participants (aged 6-12 years) towards positive experiences and interactions.

Games and gamification: Games and gamified approaches are making headway as solutions for training participants to identify and handle incidents of bullying [20,77]. This includes detecting and preventing bullying [21], improving bystander behavior and reactions [77], reducing emotional aggressiveness [92], inculcating attitude changes [114], nurturing empathy [113], bringing out positive social skills [136], and teaching concepts of digital well-being and citizenship [66]. StopBully [114], developed by researchers in Portugal, is a therapy-based serious game that utilizes role-playing, as a victim or bystander, within the context of a scenario or narration to simulate real world situations. Participants, aged 9-14 years, take actions within the games, which have consequences, and which can later be unpacked together with a therapist to create empathetic behavior change. Kriglstein et al. [81] developed and evaluated two games, one with free exploration and one with guided narration, with participants aged 11-15 years in Austria "to raise awareness of the consequences of bullying among adolescents by putting them into the role of a bystander". Serious games have also been utilized to prevent and address cyberbullying, as CalvoMorata et al. [20] show in the review of 33 such games. Their list of games reviewed targeted different groups of people - students of all ages, and parents and teachers, and employed various strategies to address bullying and cyberbullying, including raising awareness, creating empathy, and developing social and emotional skills. Addressing cyberbullying requires inculcating critical problem-solving approaches [147], in addition to social and online support systems to report and remove harmful content.

Robots and chatbots: Young et al. [154], employed chatbots with three different profiles, of a bully, a victim, and a teacher, with eighty-nine students in fifth grade (aged 11-12 years) in South Korea to determine conversations with which profile elicit the most change in the attitude towards bullying, and noted changes in the students' attitudes towards anti-bullying factors. FearNot! [6] is a virtual storytelling application that translated drama-based conflict resolution to a virtual yet realistic world, where virtual actors (characters) pause and receive advice from the audience. FearNot! has been employed with participants aged 7-12 years in the UK $[58,59]$, Germany $[45,146]$, and Portugal [144]. More recently, the use of robots has been explored or imagined for playful interactions that increases also empathy with peers, and could improve emotional regulation, e.g., the EmotoTent design fiction by [3], social engagement [13], and for identifying and mapping physical bullying gestures and behaviors [139]. Bethel et al. [13] studied witness accounts of bullying to human vs robot child-interviewers in the USA with participants aged 8-12 years. Their study found that "children may be less likely to be misinformed by the robot interviewer compared with the human interviewer", and that they are able to also share more sensitive information with the robotinterviewer. The future potential of this is immense, including, as the authors mention in their work, eliminating subconscious influences on children by human-interviewers in sensitive and delicate situations. However, there are concerns regarding how children understand the role of the robot-interviewer, which is to collect information and that is to be ultimately processed by a human [13].

Surveillance and monitoring technologies: The literature also includes several examples in which technology has been harnessed to monitor and control people for the identification or elimination of bullying (e.g. [18, 48, 53, 60]). Gao \& Ye [53] propose an automatic physical and verbal bullying detecting method for schools in China. Han et. al. [60] conducted a violence simulation experiment and designed emotion recognition and school violence detection from children's speech. The simulation was tested in a Finnish elementary school. Ferdinando et. al. [48] propose Violence Detection (VITEC) as a possible framework to facilitate multidisciplinary researchers in their fight against violence. It detects violence using physiological signals and activity recognition, and surveillance video. The authors state that "the existing school violence/bullying intervention programs can take advantage of VITEC by providing almost instant notifications of violent events, enabling the victims to get immediate help and intensifying coordination among different sectors to fight against violence" [48]. Brahnam et al. [18] propose a bullying detection/alert system for school-wide intervention in the USA that combines heartrate (HR) monitors, surveillance cameras, multimodal machine learning, cloud computing, and mobile devices. This system alerts school personnel when potential bullying is detected. The system identifies potential bullying by tracking and assessing the proximity of known bullies to known students at risk for bullying; by monitoring stress levels of students via HR analysis; and by recognizing actions, emotions, and crowd formations associated with bullying [18]. Monitoring based methods have also been applied for studying younger children's behavior and emotions. Yue et al. [151] developed a system which portrays cognitive learning rules and mental states of young children. They placed small cameras into kindergarten rooms of 2-7 years old children in China, and during each 30-minute class the cameras captured children's facial expressions every 10 seconds. The system detects children with abnormal behavior such as violent mood and notifies parents and teachers [151].

In the context of cyberbullying, monitoring can be implemented by analyzing online text messages and content to identify words 
or phrases that signify abuse, hate-speech, or threats in online social media platforms such as Facebook, Twitter, and YouTube $([29,35,41,68,78,88,125,128,135])$. This includes labeling content, text, and messages, for instance with community-driven approaches such as user likes (and dislikes) or then automated textual analysis to mark malicious words and phrases. While labeling content is helpful, in many instances, such content can be filtered or sorted to avoid it altogether [35]. Further, to improve monitoring of content, text analysis can be coupled with an analysis of social network structures [41, 68]. In this vein, Huang et al. [68] investigated whether analyzing social network features can improve the accuracy of cyber bullying detection using Twitter data. By analyzing the social network structure such as number of friends, network embeddedness, and relationship centrality detection of cyber bullying could be significantly improved [68]. Technology to detect verbal bullying online through emotion recognition in speech and text has had varying levels of success (e.g. [35, 68, 88]). Labeling or filtering content has not always been the goal. For example, Lieberman et al. [89] explored the potential of reflective interfaces where participants, aged 18 to 22 years in the USA, engaged in nuanced discussions around crowdsourced stories of bullying, similar to their experiences. Macbeth et al. [91] further propose an intelligent system that can be searched for stories or narration on stereotypical cyberbullying incidents matching actual experiences, to provide guidance and support to victims of bullying.

Challenges towards cyberbullying: Particularly related to cyberbullying, it has also been acknowledged that there still are several challenges towards identifying and addressing it [7]: this includes non-reporting of incidents for fear of victim-blaming, for being socially active and subsequently for fear of losing internet privileges, and for publicizing further a possible already public humiliation. There are also difficulties with identifying the intent or motivation of the bully and what is and is not cyberbullying (vs. online pranks) [7, 35, 36]. Further still, even if the incidents are reported, school educators, counsellors, or parents might be unable to competently handle the situation, indicating a need for systematic trainings and interventions and resources $[1,39,72]$. Cyberbullying has been associated with mental health concerns, such as depression and social anxiety $[14,74]$ and loneliness [120]. The complex and perpetual nature of cyberbullying where the bullied is likely to become a bully, requires further attention. Lozano-Blasco, Cortés-Pascual, \& Latorre-Martínez [90] reveal that the most important factor for being a cyberbully was having previously been a cyber-victim, through analysis of studies with children between 11-18 years across the world. This duality of cyber victim-bully is further associated with low social competence, higher rates of depression and social anxiety, and low mental wellbeing. Children from unstable family environments or with troublesome parenting styles were prone to being victimized in the first place [90]. Reducing, preventing, and intervening in cyberbullying can thus recursively reduce also future bullies and bullying.

As evident, many studies deploy technology mediated solutions, however, long-term adoption of such solutions is presently understudied. Further, cyberbullying has its own unique issues including the sheer scale and reach of social media, the little time it takes to spread harmful content, the potential for anonymity of the bully, and possibilities to duplicate and replicate content [35].
While anonymity afforded in online communication is considered integral to cyberbullying, studies have shown that "much of the cyber bullying occurs within the context of [victim's] social groups and relationships" $[72,100]$. Bystander effects are also visible in cyberbullying, where defending behaviors are more likely in the absence of other bystanders [28, 131]. Agatston et al.'s [1] study with 12-17 years old participants in the USA showed that students were unaware of "how to respond as a helpful bystander when witnessing cruel online behavior", indicating the need for interventions and information for handling and addressing cyberbullying in situ by bystanders. Cyberbullying, thus, is just as important to address in schools as is bullying overall $[1,72,108]$. Educating both children and adults (educators, admins, parents) on what is, and is not, (cyber)bullying and on the healthy approaches to addressing and handling it as well as the victims are needed, with technology mediated interventions for monitoring, mitigating, and preventing (cyber)bullying .

4.2.2 Against Bullying with Design. The HCI field does not only see technology as a solution for addressing bullying, but also design. One could even say that the mainstream of studies around bullying and children in $\mathrm{HCI}$ include some sort of participatory design effort to find solutions to prevent and mitigate bullying (see e.g. [5, 8 , $38,46,57,132,143])$, even if in our overall dataset this type of studies did not dominate. The goal of these studies is to strengthen social cohesion and atmosphere of a specific class or school [119, 142] or prevent cyber bullying in general [5, 142]. Participating children are primary school aged, typically around 10 years old. More specifically in [38] and in [143] participants were 9-10 years old; in [119] participants were 8-11, in [132] 6-11 and in [95] and in [113] 7-12 years of age. In some cases, the design partners were teenagers, e.g., in [5] and in [16] participants were 14-17 years old.

The studies include various kinds of design activities with children. Typical is that these design activities include a type of storytelling (e.g. [16, 38, 113, 119, 132]), drawn or written scenarios $[38,142,143]$ or making different type of storyboards $[16,113,119]$. Many studies also involve different type of prototyping activities such as in [5, 38, 142, 143] and paper protyping [95]. Also discussions $[16,113,119]$ and prototype testing and/or evaluation $[5,113,119]$ are mentioned in several studies. Scenarios and stories are used in design activities in different ways for different purposes. Children may create them as design tasks, drawing from their personal experiences and imagination (e.g. $[119,142])$ or they might work as inspiration material by researchers or other professionals as scenario centers in [5] and scenarios made by a psychological team in [119].

The design studies in the literature tend to have heavily a problem-focused approach to bullying. For example, in [38] the design sessions with children start with analyzing the problematic class situations. Also in [119] children were asked to represent and reflect individually, or collaboratively, on situations involving conflict in the classroom context. In addition, in [5] participants conducted a pre-survey dealing with e.g. former bullying experiences. This data was used for tailoring further design sessions. A refreshing exception to problem-focused approaches is [132] which presents more solution-focused method for bullying prevention. In this study, storytelling shapes -toolkit enables children to express 
Table 1: Underlying assumptions in the literature

\begin{tabular}{|c|c|c|}
\hline Analytic focus & Underlying assumptions & In $\mathrm{CHI}$ research \\
\hline \multicolumn{3}{|l|}{$\begin{array}{l}\text { How to study } \\
\text { bullying? }\end{array}$} \\
\hline Questions asking & $\begin{array}{l}\text { Humans passive providers of information, objects of } \\
\text { observation }\end{array}$ & Often used in combination with other methods \\
\hline Reflection arousing & Humans active agents making sense of the world & A strength of $\mathrm{CHI}$ research \\
\hline $\begin{array}{l}\text { Hands-on engagement } \\
\text { How to approach } \\
\text { bullying? }\end{array}$ & Humans active agents making a change in the world & Particular strength of $\mathrm{CHI}$ research \\
\hline \multirow[t]{2}{*}{ Through technology } & Humans passive objects of observation & $\begin{array}{l}\text { Technology for control, surveillance, } \\
\text { monitoring, detection of bullying }\end{array}$ \\
\hline & Humans active agents making a change in the world & $\begin{array}{l}\text { Technology arousing human empathy and } \\
\text { agency }\end{array}$ \\
\hline Through design & Humans active agents making a change in the world & Particular strength of $\mathrm{CHI}$ research \\
\hline $\begin{array}{l}\text { Through a } \\
\text { problem-focused } \\
\text { approach }\end{array}$ & $\begin{array}{l}\text { Understanding and addressing the problem is needed } \\
\text { before solving it }\end{array}$ & Heavy emphasis in $\mathrm{CHI}$ research \\
\hline $\begin{array}{l}\text { Through a } \\
\text { solution-focused } \\
\text { approach }\end{array}$ & $\begin{array}{l}\text { Instead of problems, the focus should be on strengths and } \\
\text { positive futures }\end{array}$ & Few mentions in $\mathrm{CHI}$ research \\
\hline $\begin{array}{l}\text { Through an } \\
\text { individualistic approach }\end{array}$ & $\begin{array}{l}\text { Bullying an individual problem, individual responsibility, } \\
\text { requiring individual action taking }\end{array}$ & $\begin{array}{l}\mathrm{CHI} \text { research focuses on human-technology } \\
\text { interaction and use }(\mathrm{r}) \text { experience }\end{array}$ \\
\hline $\begin{array}{l}\text { Through a collective } \\
\text { approach }\end{array}$ & $\begin{array}{l}\text { Bullying a social problem, collective responsibility, } \\
\text { requiring collective action taking from an entire social } \\
\text { system }\end{array}$ & $\begin{array}{l}\mathrm{CHI} \text { research focuses more at the micro level } \\
\text { collaboration in groups, less at the macro level }\end{array}$ \\
\hline
\end{tabular}

their needs and wishes by creating a tangible story about things they like to do with others.

\section{DISCUSSION}

This section summarizes the main findings and discusses their research and design implications.

\subsection{Varying Assumptions About Design, Technology, and Human Agency}

Based on the literature review, interesting assumptions characterizing existing research can be identified. Those revolve around human nature, the nature of bullying intervention, and the potential of design and technology within. Table 1 . summarizes the findings of this study.

Table 1 illustrates that there is a variety of research methods employed to address bullying in CHI. One can identify quite traditional research methods, such as interviews and observations, which seem very common within other disciplines addressing bullying (see the Appendix), but are usually used in combination with other methods in CHI: they are often used during a pre-study phase before using reflection or creative, hands on type of methods (see e.g. [5, 119]). Such methods place the participants into relatively passive positions as providers of information and objects of observation. We think $\mathrm{CHI}$ research can truly contribute to bullying research with its method repertoire, those methods aiming at arousing participant reflection, including for instance storytelling and drama-based methods (see e.g. [57, 113, 119, 132, 138]) or even empowering participants to start designing and making proposals for change (see e.g. $[5,113,142])$. These methods clearly hold alternative assumptions about the human being, who are seen as capable for reflection and sense making as well as for action taking for the better world. We, however, identified a lack of therapeutic methods in $\mathrm{CHI}$ as well as in research on bullying more generally. To address this gap, we later propose guidelines on such methods so that their fundamental principles could be used to inspire and guide $\mathrm{CHI}$ research.

Table 1 also illustrates that several distinctions can be identified from $\mathrm{CHI}$ research concerning the nature of the means with which one is expected to tackle bullying. A common feature in computing research is to suggest technology-mediated solutions. Our review identified a huge number of those. However, we also identified a lot of variety within. The literature includes several examples in which technology has been harnessed to monitor and control people for the identification or prevention of bullying (e.g. [18, $29,35,48,53,60,68,125,151])$ : in these cases, technology aims to identify instances of bullying and sends out notifications or alerts. In such cases, nurturing of human agency is clearly not in focus. More room for human agency is offered in various kinds of solutions for identification and reporting of bullying incidents done by humans. Moreover, plenty of educational solutions have been introduced for awareness raising and behavior change (e.g. $[95,117,123,137])$, including different kinds of games and gamified solutions (e.g. [21, 77]). Technology may also facilitate participant role-play and drama acting (e.g. [6, 45, 133, 154]), for exploring and experiencing bullying related situations. Empathy building $[3,113$, 
114] and bringing out positive social skills [136] in participants may be the goals of such solutions, which may even include engagement with a therapist to create empathetic behavior change [114]. Hence, we see a trajectory forming from strong technology control to priority for human empathy and agency.

Not only technology is seen as a solution, but also design: the literature includes several studies reporting on participatory or codesign activities of children, addressing bullying (e.g. [5, 38, 46, 57, $132,142]$ ), these studies clearly allowing room for human agency as regards bullying. Even if these studies from a minority in our overall dataset, they are common in the HCI field. These studies have included design and making of solutions of various kind to tackle bullying as well as more general aims relating to strengthening social cohesion and atmosphere of a specific class or school [119, 142]. In many of the studies the work has entailed exploring current problems [38, 95, 119, 142, 143], while interestingly in some studies the focus has rather been on positive futures than problematic currents [132]. In some of the studies also drama-based methods have been experimented with [113] or a psychological team has been engaged [119].

As is evident, in many technology and design based approaches there has been an emphasis on the problems; on their detection, surveillance, reporting. However, we have also identified, inspired by the solution-focused therapy [37, 155], studies that do not delve in the problem of bullying but rather try to rely on and nurture the existing strengths and positive aspects: some evidence for such could be identified from technologies aiming at bringing out positive social skills [136] as well as from design sessions in which children tell what they like to do with others [132].

Moreover, the solution-focused therapy approach [37, 155] enabled us to distinguish between individual and collective focused approaches. The monitoring, surveillance and detection focused solutions do not try to engage a community around the topic. Many reporting, educational and game-based solutions also seem targeted for an individual. It seems this literature assumes bullying is an individual problem and elimination of it is individual responsibility, requiring individual action taking. On the other hand, interaction among the participants is also facilitated in many technology based solutions: for example in case of robots, chatbots or virtual worlds, social aspects are underscored [3, 6, 45, 113, 114, 133, 154]. The same goes for participatory or co-design sessions, in which children are invited to collaboratively address common issues in their class or school [5, 38, 46, 57, 132, 143]. Even if it is not entirely clear how broadly the studies strive for collective responsibility and action taking, they clearly employ a view of bullying as a social problem and collective responsibility that requires collective action taking from an entire social system. The studies variably bring up stakeholder groups and roles associated with bullying of children. In addition to children themselves, teachers, schools and parents are often mentioned. However, we did not find a lot of research explicitly engaging all key actors within the social system to take part in finding solutions for making the school a happy place for all; where everyone is helping others to feel good and to enjoy their stay (cf. [155]).

We argue the basic assumptions underlying research on bullying can be nicely mapped with constructs adopted from management research, combined with current understanding from solution-focused therapy (Figure 1): The basic assumptions about the human being in Theory $\mathrm{X}$ and $\mathrm{Y}$, introduced in management research by McGregor (e.g. [24, 79]) enable capturing interesting distinctions in the literature on bullying, combined with the individualistic vs. collective focus and problem vs. solution focus as introduced in the solution-focused therapy literature (see e.g. $[37,155])$. Part of the literature we reviewed on bullying seems clearly to rely on Theory X assumptions about the human being: it holds a pessimistic assumptions that people are lazy and unmotivated to work against bullying as such and therefore they need to be monitored, controlled, surveyed, and pushed to achieve a desired outcome. People are assumed to avoid taking responsibility of bullying. In case they do, this is approached as individual responsibility and action taking. The focus is heavily on problem identification. The literature holding theory Y assumptions, then again, relies on more optimistic assumptions about the human being: collaborative and participatory approach is to be utilized in bullying interventions, people are seen as taking responsibility for bullying and being self-motivated for action taking, taking ownership and relying on their own initiative. In addition, action taking is broadly considered as a collective process, involving a whole social system, while it is seen that the focus on the entire endeavor should rather be on envisioning and creating positive futures together than on delving on the problems of today.

However, we wish to point out that the distinctions identified do not necessarily imply an either-or choice, but different kinds of approaches can be combined: solution and problem focused, individual and collective focused, design and technology focused. Then again, we also wish to underscore to the $\mathrm{CHI}$ community that the underlying assumptions about the human beings tend to be unconsciously embedded into our practices and tools we develop, representing our deep worldviews and values, which are in some cases contradictory and which cannot all be combined. Overall, we maintain that reflecting on these underlying assumptions and values is valuable for the $\mathrm{CHI}$ community, also in relation to other topics than bullying.

\subsection{Solution-Focused Therapy Meets CHI \& Bullying}

As mentioned, our work has been inspired by solution-focused therapy approach to bullying. It has enabled us to reveal interesting themes and distinctions in prior research, while we think it should also be used to inspire our future technology and design projects. We acknowledge that some studies have already brought up therapeutic games and collaboration with therapists or psychologists in relation to bullying interventions $[114,119]$, but so far, they are few in CHI. Then again, we do acknowledge that therapy-based games for children are common in the context of special needs, disabilities (physical, neurological, acquired injuries etc.), and rehabilitation, so the concept is not new to $\mathrm{CHI}$ in that sense. However, it seems that therapy-based games towards prevention of bullying are missing in CHI. The benefit of employing therapy-based approaches (e.g. [155]), which are structured on understanding human nature and behaviors (see for example [54] in the context of special needs) to address bullying can be several, including considering both the bully and victim as equal actors who require positive transformations 


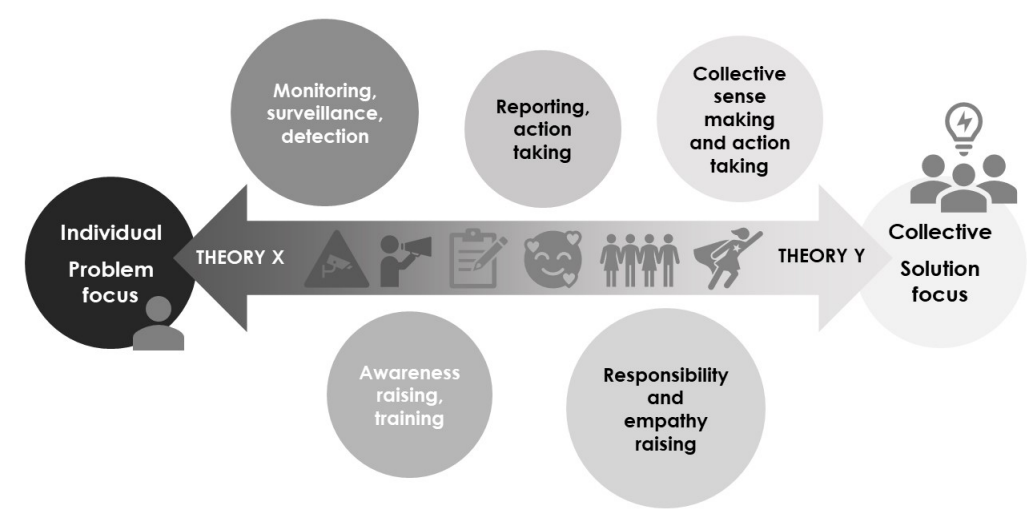

Figure 1: Continuum of $\mathrm{CHI}$ bullying research spanning from theory $\mathrm{X}$ of individual and problem focused methods to theory $\mathrm{Y}$ of collective and solution focused methods.

in their mindsets, attitudes, and mental health, cutting short the recursive and destructive cycle of (feeling of) victimization and the bullied from becoming the bully, and providing social support and tools to deal with everyday life challenges and experiences. [116]

Borrowing from therapy-based solutions and interventions, participatory and co-design approaches can benefit by approaching the challenges of bullying together with different stakeholders - the bully, the bullied, the bystanders, and recognizing adult/social roles and responsibilities of parents, teachers, therapists and counsellors. If the goal is for a happier and more positive school experiences for all involved, then all should be involved in devising ways to mitigate and address bullying. By integrating a therapy-based approach into participatory design, we wish to emphasize the integration between research methods of inquiry and design. We not only highlight the importance of education-oriented reflection, awareness raising, sense making and changing of behavior of individuals, but we enlarge our focus into more discursive and dialogical interventionist approaches typical for therapeutic approaches, relying heavily on dialogical questions and transformation of the attitudes and mindsets. The desire for positive change in the future is there, together with a collaborative approach as in participatory design, but the innovation and design processes are more focused on the shared meanings making typical for dialogical process. The voice of children (as well as other actors) is heard and their assumptions become shared as well as challenged while asking and answering investigative type of questions regarding wellbeing. At the same time, strengths and relationship capabilities are increased while outstandingly praising every small step towards the desired, positive future. Digital technology is seen as potential enabler of the envisioned future, i.e. as part of the solution. Typical for a therapeutic process, the process is goal-directed and focuses on coaching and supporting the change needed in those involved in order to live happier life. Finally, we want to highlight the potential of design as a way to encourage participants to play around with their potential scenarios and visions of positive future, again with reflective thinking and discussions in situ playing a significant role as well as experimenting with the design outcomes and exploring their potential.
As is obvious, we do not suggest $\mathrm{CHI}$ to utilize the solutionfocused approach literally; instead, we highlight some core issues that we think form foundation principles for the future therapybased participatory design approach. First, instead of problem-based approach, we suggest an approach focused on social behavior opposite of bullying: instead of decreasing or preventing undesired behavior, it is suggested to focus on favorable behavior such as promoting friendships and compassion, respecting each other as well as supporting and helping each other [155]. We suggest trying to avoid using the concept of "bullying" in everything done. In addition, above mentioned interventionist approach with collaboration and teamwork are highlighted. The focus is to be on bottom-up participatory approach, where children 's own voices are heard, with the aim that all school children are happy. Nobody is judged (as a bully or a victim); instead, everyone is considered capable to find solutions for making the school a happy place for all where everyone is helping others to feel good and to enjoy their stay. Therefore, all children are considered potential participants in this process. Following the idea of a "support group for the suffering child" [155] we recommend focusing on the group effort, all children being seen as capable to brainstorm and codesign for "better" future. We would like to encourage schoolchildren to think "how they can help those who are not feeling good at school to feel better?"

Young [155] introduces a gradual process which we consider similar to an iterative design process. First, we would like to encourage children to brainstorm for the enjoyable school of the future where everyone feels happy. Next, in line with Young's "support group" taking new ideas into practice, we encourage children to test their ideas in practice before moving to the following steps in the design process. The importance of reflection in and after action is to be highlighted. Positive feedback is to be given frequently [37]. Following the solution-focused approach, we want to keep discussions focused on the future instead of the present. We also aim for as detailed discussions about the future as possible with the support of solution-focused inquiring questions. We consider this as one of the most important guidelines when coaching and supporting the design process; to sensitively direct discussions towards future whenever they seem to fall into problems. It is also important 
to understand that we should not intentionally avoid discussions about bullying. In situations when the participants feel the need to describe the problems they have had; one needs to let them do so. However, we do not want to discuss these problems further in detail, instead, we turn the focus into future where these problems have been solved. While doing this, similar to solution-focused therapy approach, we value all the attempts that have already been done towards solutions, all the practices that are already working, including positive deviations [37]. We might even study the details of those positive deviations especially when designing digital technology to enhance them. We also want to consider the use of different type of scaling questions when possible [37]. For example, after each design session we could ask how well the solution works now and how to make it even better. Finally, we want to highlight the usefulness of "miracle question" and the questions following that [37]. In the miracle question, it is expected that during sleep a miracle happens and the problem is gone. Then, we start to ask several questions pointing to the details by which people become aware of the change that has happened due to the miracle; how to recognize the difference, who recognizes what etc. In addition, we would like to highlight the importance of right kind of questions when envisioning the future. Questions highlighting relationships and interaction between people involved are important and useful [37]: we want our participants to consider who the people involved are and how each of them sees things after the potential changes.

We wish to acknowledge also recent developments in the field of solution-focused therapy. The strength-oriented techniques and the method of "co-construction of meaning" used for building solutions with clients picture strong in solution-focused therapy, while there is a need to understand better the way the approach uses the co-construction process and how to facilitate this process [52]. Furthermore, the impact of the collaborative, co-constructive discussion approach, described as "client-led language", making the client feeling understood and cared for, for a meaningful change process should be studied further [52]. All in all, we think these paths for future work within solution-focused therapy reveal potential for transdisciplinary gains when combined with human-centered and participatory approaches within HCI research.

\subsection{Ethics Underscored}

We wish to emphasize that we are dealing with a very sensitive topic with many ethical issues involved. This is partly addressed by the literature reviewed, while there is still room for elaboration. The literature shows there are solutions developed for monitoring bullies and students at risk for being bullied as well as solutions detecting children's facial expressions and alerting adults when identifying abnormal behavior. The goal of such solutions is indeed valuable, i.e. prevention of bullying and safeguarding of children, but there are also risks of stigmatizing and of advocating a true surveillance society with all our facial expressions being constantly monitored by authorities with alerting mechanisms in place. Moreover, one common pitfall in most of the previous research on bullying is the limited focus on what makes a bully - addressing the potential factors that can increase the likelihood of a child becoming a bully. Instead, alarmingly, technology mediated interventions, especially those dealing with cyberbullying and surveillance, are geared towards labeling individuals - as a bully or a victim, possibly reducing their identities to specific instances, which we speculate can further propagate feeling of and stigma around victimization for the victim and limit avenues of reformation or getting help for the bully. There is an alarming dynamic identified around those formerly bullied becoming bullies. Collective action and responsibility need to be taken to prevent this from happening. Finally, we wish to highlight that we do not recommend solution-focused therapy use by non-expert CHI researchers. We have adopted ideas and inspiration from solution-focused therapy, while we acknowledge its proper use requires extensive expertise.

\section{CONCLUSIONS}

In this study we addressed an unfortunately common and a complex phenomenon of bullying through conducting a critical literature review on studies tackling bullying in the lives of children, in the context of and/or by the means of design and technology, covering $\mathrm{CHI}$ as well as related computing fields, being inspired by the strong body of knowledge within human sciences. We reported what and how has been done so far to handle this troublesome and widespread phenomenon, revealed interesting underlying assumptions about design, technology and human agency in the literature as well as suggested how to move the field forward with a combination of solution-focused therapy, technology mediated interventions and participatory design.

We acknowledge that the literature review has several limitations. We excluded studies on adults, even if adults most certainly experience as well as suffer from bullying equally to children. Moreover, we did not include studies on the nature, extent, causes or consequences of bullying in children's lives - our focus was on studies working against bullying, not on studies only empirically examining it. Some of the papers touched upon the causes and consequences of bullying, but it would require other reviews (on other disciplines than $\mathrm{HCI}$ ) to be able to say something substantial about these topics. Furthermore, we did not specifically examine the effects of children's age on the results. We note that the majority of the studies addressed school aged children (K-12), while pre-school aged children received little attention (see the Appendix). Additionally, we did not take into account the effect of gender, if reported in the studies at all. Demographic factors deserve more thorough treatment in the future. As for limitations, further, we did not concentrate much on contextual factors in bullying. We acknowledge cultural issues play a role in bullying as well as in interventions designed against it: cultural contexts shapes what is considered as bullying and what is considered as appropriate in dealing with it. According to our review, bullying research seems to be heavily concentrated on the Western world. In this literature review most of the studies were conducted in European countries or in North America. However, there was also some cultural variety as some studies conducted in Asia, Australia, Middle East and South America were included as well. Moreover, many studies examined English language social media data that can be considered global. However, studies in the context of Global South or developing countries were very limited. Further studies in these contexts are warmly welcomed. Overall, our dataset addressed cultural issues in the sense of variety of countries and continents, while we 
acknowledge cultural aspects in bullying deserve a more thorough treatment and argue for culture specific guidance for future interventions against bullying, in $\mathrm{CHI}$ as well as elsewhere. We also acknowledge that bullying as a concept is closely related to concepts such as violence and aggression, which were not specifically examined in our literature review, even if touched upon in many studies. Some even claim that bullying is too mild of a concept and that one should always use the concept of violence instead of bullying to make visible the seriousness and harmfulness of the phenomenon we are dealing with. We will explore the relations between these concepts further in the future. We also invite the $\mathrm{CHI}$ community to continue examining how aggression and violence picture in the $\mathrm{CHI}$ discourse, how those are impairing the lives of adults and children alike and how design, technology, and therapy could make a difference.

\section{ACKNOWLEDGMENTS}

This study was funded by Academy of Finland (Grant \#324685, Make-a-Difference project). This research is connected to the GenZproject, a strategic profiling project in human sciences at the University of Oulu, supported by the Academy of Finland (Grant \#318930) and the University of Oulu.

\section{REFERENCES}

[1] Patricia W. Agatston, Robin Kowalski and Susan Limber. 2007. Students' Perspectives on Cyber Bullying. Journal of Adolescent Health 41 (6 SUPPL.): S59-S60. https://doi.org/10.1016/j.jadohealth.2007.09.003

[2] Álvarez-García, D., García, T. and Núñez, J.C., 2015. Predictors of school bullying perpetration in adolescence: A systematic review. Aggression and Violent Behavior, 23, pp.126-136.

[3] Alissa N. Antle, Ofir Sadka, Iulian Radu, Boxiao Gong, Victor Cheung, and Uddipana Baishya. 2019. EmotoTent: Reducing School Violence through Embodied Empathy Games. In Proceedings of the 18th ACM International Conference on Interaction Design and Children (IDC '19). Association for Computing Machinery, New York, NY, USA, 755-760. https://doi.org/10.1145/3311927.3326596

[4] Asher, Y., Stark, A. and Fireman, G.D., 2017. Comparing electronic and traditional bullying in embarrassment and exclusion scenarios. Computers in Human Behavior, 76, pp. 26-34

[5] Zahra Ashktorab and Jessica Vitak. 2016. Designing Cyberbullying Mitigation and Prevention Solutions through Participatory Design With Teenagers. In Proceedings of the $2016 \mathrm{CHI}$ Conference on Human Factors in Computing Systems (CHI '16). Association for Computing Machinery, New York, NY, USA, 3895-3905. https://doi.org/10.1145/2858036.2858548

[6] Ruth Aylett, Sandy Louchart, João Dias, Ana Paiva, Marco Vala. 2005. FearNot! - An Experiment in Emergent Narrative. International Workshop on Intelligent Virtual Agents, 305-316. Springer, Berlin, Heidelberg. https://doi.org/10.1007/ 11550617_26

[7] Niels Baas, Menno De Jong, and Constance Drossaert. 2013. Children's Perspectives on Cyberbullying: Insights Based on Participatory Research. Cyberpsychology, Behavior, and Social Networking 16 (4): 248-253. https://doi.otg/10. 1089/cyber.2012.0079

[8] Karla Badillo-Urquiola, Diva Smriti, Brenna McNally Evan Golub, Elizabeth Bonsignore, and Pamela J. Wisniewski. 2019. Stranger Danger! Social Media App Features Co-designed with Children to Keep Them Safe Online. Proceedings of the 18th ACM International Conference on Interaction Design and Children 394-406. https://doi.org/10.1145/3311927.3323133

[9] Glenda J.L. Battey and Vicki Ebbeck. 2013. A Qualitative Exploration of an Experiential Education Bully Prevention Curriculum. Journal of Experiential Education 36 (3): 203-17. https://doi.org/10.1177/1053825913489102

[10] Linda Beckman, Curt Hagquist and Lisa Hellström. 2013. Discrepant Gender Patterns for Cyberbullyiyng and Traditional Bullying - an Analysis of Swedish Adolescent Data. Computers in Human Behavior 29 (5): 1896-1903. https://doi org/10.1016/j.chb.2013.03.010

[11] Maria Beltrán-Catalán, Izabela Zych, Rosario Ortega-Ruiz, and Vicente J. Llorent. 2018. Victimisation through Bullying and Cyberbullying: Emotional Intelligence Severity of Victimisation and Technology Use in Different Types of Victims. Psicothema 30 (2): 183-88. https://doi.org/10.7334/psicothema2017.313

[12] Beran, T., Mishna, F., McInroy, L.B. and Shariff, S., 2015. Children's experiences of cyberbullying: A Canadian national study. Children \& Schools, 37(4), pp.207-214
[13] Cindy L. Bethel, Zachary Henkel, Deborah Eakin, David. C. May, and Melinda Pilkinton. 2017. Moving Toward an Intelligent Interactive Social Engagement Framework for Information Gathering. https://doi.org/10.1109/SAMI.2017. 7880307

[14] Rina A. Bonanno and Shelley Hymel. 2013. Cyber Bullying and Internalizing Difficulties: Above and Beyond the Impact of Traditional Forms of Bullying. Journal of Youth and Adolescence 42 (5): 685-697. https://doi.org/10.1007/s10964013-9937-1

[15] Tibor Bosse Sven Stam. 2011. A normative agent system to prevent cyberbullying. In 2011 IEEE/WIC/ACM International Conferences on Web Intelligence and Intelligent Agent Technology (Vol. 2, pp. 425-430). IEEE. https://doi.org/10.1109/ WI-IAT.2011.24

[16] Leanne Bowler, Cory Knobel \& Eleanor Mattern. 2015. From cyberbullying to well-being: A narrative-based participatory approach to values-oriented design for social media. Journal of the Association for Information Science and Technology, 66(6), 1274-1293. https://doi.org/10.1002/asi.23270

[17] Bradshaw, C.P. and Johnson, R.M., 2011. The social context of bullying and peer victimization: An introduction to the special issue. Journal of School Violence, 10(2), pp.107-114.

[18] Sheryl Brahnam, Jenifer J. Roberts, Loris Nanni, Cathy L. Starr and Sandra L. Bailey. 2015. Design of a Bullying detection/alert System for School-Wide Intervention. Lecture Notes in Computer Science (Including Subseries Lecture Notes in Artificial Intelligence and Lecture Notes in Bioinformatics). Vol. 9170. https://doi.org/10.1007/978-3-319-20916-6_64

[19] Steven Lawrence Brewer Jr, Hannah Meckley-Brewer, and Philip M. Stinson. 2017. Fearful and Distracted in School: Predicting Bullying among Youths. Children \& Schools 39 (4): 219-26. https://doi.org/10.1093/cs/cdx021

[20] Calvo-Morata, A., Freire-Morán, M., Martínez-Ortiz, I., \& Fernández-Manjón, B. (2019). Applicability of a cyberbullying videogame as a teacher tool: Comparing teachers and educational sciences students. IEEE Access, 7, 55841-55850.

[21] Antonio Calvo-Morata, Dan Christian Rotaru, Cristina Alonso-Fernández, Manuel Freire, Iván Martínez-Ortiz \& Baltasar Fernández-Manjón. Validation of a cyberbullying serious game using game analytics. IEEE Transactions on Learning Technologies. https://doi.org/10.1109/TLT.2018.2879354.

[22] Antonio Calvo-Morata, Dan Cristina Alonso-Fernández, Manuel Freire, Iván Martínez-Ortiz \& Baltasar Fernández-Manjón 2020. Serious games to prevent and detect bullying and cyberbullying: A systematic serious games and literature review. Computers \& Education, 157, 103958. https://doi.org/10.1016/j.compedu. 2020.103958

[23] Marilyn Campbell, Barbara Spears, Phillip Slee, Des Butler and Sally Kif. 2012. Victims' Perceptions of Traditional and Cyberbullying, and the Psychosocial Correlates of their Victimisation. Emotional and Behavioural Difficulties 17 (3-4): 389-401. https://doi.org/10.1080/13632752.2012.704316

[24] Charles M. Carson. 2005. . "A Historical View of Douglas McGregor's Theory Y." Management Decision 43 (3): 450-460. https://doi.org/10.1108/ 00251740510589814

[25] José A. Casas, Rosario Del Rey and Rosario Ortega-Ruiz. 2013. Bullying and Cyberbullying: Convergent and Divergent Predictor Variables. Computers in Human Behavior 29 (3), 580-587. https://doi.org/10.1016/j.chb.2012.11.015

[26] Chalamandaris, A.G. and Piette, D., 2015. School-based anti-bullying interventions: Systematic review of the methodology to assess their effectiveness. Aggression and violent behavior, 24, pp.131-174.

[27] Chan, H.C.O. and Wong, D.S., 2015. Traditional school bullying and cyberbullying in Chinese societies: Prevalence and a review of the whole-school intervention approach. Aggression and Violent Behavior, 23, pp.98-108.

[28] Nee Nee Chan, P. Ahrumugam, Herbert Scheithauer, Anja Schultze-Krumbholz, and P. B. Ooi. 2020. A Hermeneutic Phenomenological Study of Students' and School Counsellors' "lived Experiences" of Cyberbullying and Bullying. Computers and Education 146. https://doi.org/10.1016/j.compedu.2019.103755

[29] Yunfei Chen, Lanbo Zhang, Aaron Michelony, and Yi Zhang. 2012. 4Is of social bully filtering: identity, inference, influence, and intervention. In Proceedings of the 21st ACM international conference on Information and knowledge management (CIKM '12). Association for Computing Machinery, New York, NY, USA, 2677-2679. https://doi.org/10.1145/2396761.2398723

[30] Chen, Y.T. and Li, C.C., 2014, September. Study of service innovation on School Bullying treatment with inviting Knowledge Management features. In 2014 IEEE International Conference on Management of Innovation and Technology (pp. 306-311). IEEE.

[31] Li-Ming Chen. 2015. Self-Reported Frequency and Perceived Severity of being Bullied among Elementary School Students. Journal of School Health 85 (9): 587-594. https://doi.org/10.1111/josh.12289

[32] Enrica Ciucci, Andrea Baroncelli, Ilaria Grazzani, Veronica Ornaghi and Claudia Caprin. 2016 .Emotional Arousal and Regulation: Further Evidence of the Validity of the "how I Feel" Questionnaire for use with School-Age Children. Journal of School Health 86 (3): 195-203. https://doi.org/10.1111/josh.12370

[33] Clarke, A.M., Kuosmanen, T. and Barry, M.M., 2015. A systematic review of online youth mental health promotion and prevention interventions. Journal of youth and adolescence, 44(1), pp.90-113. 
[34] Coelho, V.A. and Romão, A.M., 2018. The relation between social anxiety, social withdrawal and (cyber) bullying roles: A multilevel analysis. Computers in Human Behavior, 86, pp. 218-226.

[35] Robin Cohen, Disney Yan Lam, Nikhil Agarwal, Michael Cormier, Jasmeet Jagdev, Tianqi Jin, Madhur Kukreti, Jiawei Liu, Kamal Rahim, Rahul Rawat, W. Sun, D. Wang \& M. Wexler. 2014. Using computer technology to address the problem of cyberbullying. ACM SIGCAS Computers and Society, 44(2), 52-61. https://doi.org/10.1145/2656870.2656876

[36] Justin Connolly, Pamela Hussey, and Regina Connolly. 2014. TechnologyEnabled Bullying and Adolescent Resistance to Report: The Need to Examine Causal Factors. Interactive Technology and Smart Education 11 (2): 86-98. https://.doi.org/10.1108/ITSE-04-2014-0003

[37] Peter de Jong and Insoo Kim Berg. 2016. Ratkaisukeskeisen lyhytterapian oppikirja. Helsinki: Lyhytterapiainstutuutti Oy. (Original Peter de Jong and Insoo Kim Berg. 2008. Interviewing for solutions (3rd ed.). Belmont, CA: Thomson Higher Education.)

[38] Jan Derboven, Maarten Van Mechelen, and Karin Slegers. 2015. Multimodal Analysis in Participatory Design with Children: A Primary School Case Study. In Proceedings of the 33rd Annual ACM Conference on Human Factors in Computing Systems (CHI '15). Association for Computing Machinery, New York, NY, USA, 2825-2828. https://doi.org/10.1145/2702123.2702475

[39] Ann DeSmet, Nathalie Aelterman, Sara Bastiaensens, Katrien Van Cleemput, Karolien Poels, Heidi Vandebosch, Greet Cardon, and Ilse De Bourdeaudhuij. 2015. Secondary School Educators' Perceptions and Practices in Handling Cyberbullying among Adolescents: A Cluster Analysis. Computers and Education 88: 192-201. https://doi.org/10.1016/j.compedu.2015.05.006

[40] DeSmet, A., Bastiaensens, S., Van Cleemput, K., Poels, K., Vandebosch, H., Deboutte, G., Herrewijn, L., Malliet, S., Pabian, S., Van Broeckhoven, F. and De Troyer, O., 2018. The efficacy of the Friendly Attac serious digital game to promote prosocial bystander behavior in cyberbullying among young adolescents: a cluster-randomized controlled trial. Computers in Human Behavior, 78, pp.336-347.

[41] Karthik Dinakar, Birago Jones, Catherina Havasi, Henry Lieberman \& Rosalind Picard.2012. Common sense reasoning for detection, prevention, and mitigation of cyberbullying. ACM Transactions on Interactive Intelligent Systems (TiiS), 2(3), 1-30. https://doi.org/10.1145/2362394.2362400

[42] Ding, Y., Li, D., Li, X., Xiao, J., Zhang, H. and Wang, Y., 2020. Profiles of adolescent traditional and cyber bullying and victimization: The role of demographic, individual, family, school, and peer factors. Computers in Human Behavior, p.106439.

[43] Edgerton, E., Reiney, E., Mueller, S., Reicherter, B., Curtis, K., Waties, S. and Limber, S.P., 2016. Identifying new strategies to assess and promote online health communication and social media outreach: an application in bullying prevention. Health promotion practice, 17(3), pp.448-456.

[44] April Edwards, David Demoll, Lynne Edwards. 2020.Detecting Cyberbullying Activity Across Platforms. 17th International Conference on Information Technology-New Generations (ITNG 2020), 45-50. https://doi.org/10.1007/9783-030-43020-7 7

[45] Sibylle Enz, Cheryl Zoll, Nicola Vannini, Wolfgang Schneider, Lynne Hall, Ana Paiva, and Ruth Aylett. 2007. E-Motional Learning in Primary Schools: Fearnot! an Anti-Bullying Intervention Based on Virtual Role-Play with Intelligent Synthetic Characters. Electronic Journal of e-Learning, 6(2), 111-118.

[46] Eva Eriksson, Gökçe Elif Baykal, Staffan Björk, and Olof Torgersson. 2019. Using Gameplay Design Patterns with Children in the Redesign of a Collaborative Co-located Game. Proceedings of the 18th ACM International Conference on Interaction Design and Children (IDC '19). Association for Computing Machinery, New York, NY, USA, 15-25. https://doi.org/10.1145/3311927.3323155

[47] Evans, C.B., Fraser, M.W. and Cotter, K.L., 2014. The effectiveness of school-based bullying prevention programs: A systematic review. Aggression and Violent Behavior, 19(5), pp.532-544.

[48] Hany Ferdinando, Tuija Huuki, Liang Ye, Tian Han, Zhu Zhang, Guobing Sun, Tapio Seppänen and Esko Alasaarela. 2019. VITEC: A Violence Detection Framework. Lecture Notes of the Institute for Computer Sciences, SocialInformatics and Telecommunications Engineering, LNICST. Vol. 287. https: //doi.org/10.1007/978-3-030-22971-9_1

[49] Renata Ferreira, Mirna Frota, Jose de Vasconcelos Filho, Antonio Bastos, Geisy Luna \& Karla Rolim, 2020. Comparison of features of a mobile application to report school violence through benchmarking. Journal of school health, 90(4), 295-300. https://doi.org/10.1111/josh.12876

[50] Ferreira, P.C., Simão, A.V., Paiva, A. and Ferreira, A., 2020. Responsive bystander behaviour in cyberbullying: a path through self-efficacy. Behaviour \& Information Technology, 39(5), pp.511-524.

[51] Cynthia Franklin. 2015. An update on strengths-based, solution-focused brief therapy. Health \& Social Work, 40, 73-76. https://doi.org/10.1093/hsw/hlv022

[52] Cynthia Franklin, Anao Zhang, Adam Froerer \& Shannon Johnson. 2017. Solution-focused brief therapy: A systematic review and meta-summary of process research. Journal of Marital and Family Therapy, 43(1), 16-30. https: /doi.org/10.1111/jmft.12193

[53] Shangbin Gao and Liang Ye. 2019. A Physical and Verbal Bullying Detecting Algorithm Based on K-NN for School Bullying Prevention. Lecture Notes of the Institute for Computer Sciences, Social-Informatics and Telecommunications Engineering, LNICST. Vol. 287. https://doi.org/10.1007/978-3-030-22971-9 13

[54] Garzotto, F., Valoriani, M., \& Bartoli, L. (2014). Touchless motion-based interaction for therapy of autistic children. In Virtual, Augmented Reality and Serious Games for Healthcare 1, 471-494. Springer, Berlin, Heidelberg. https: //doi.org/10.1007/978-3-642-54816-1_23

[55] Goodwin, J., Bradley, S.K., Donohoe, P., Queen, K., O'Shea, M. and Horgan, A., 2019. Bullying in schools: an evaluation of the use of drama in bullying prevention. Journal of Creativity in Mental Health, 14(3), pp.329-342.

[56] Gutierrez Aponte, D.F. and Richards, D., 2013. Managing cyber-bullying in online educational virtual worlds. In Greuter, Stefan. IE2013 : proceedings of the 9th Australasian Conference on Interactive Entertainment : matters of life and death, p.1-9

[57] Lynne Hall, Sarah Woods, Kerstin Dautenhahn, and Polly Sobreperez. 2004. Using storyboards to guide virtual world design. In Proceedings of the 2004 conference on Interaction design and children: building a community (IDC '04). Association for Computing Machinery, New York, NY, USA, 125-126. https: //doi.org10.1145/1017833.1017853

[58] Lynne Hall, Marco Vala, Marc Hall, Marc Webster, Sarah Woods, Adrian Gordon \& Ruth Aylett. 2006. FearNot's Appearance: Reflecting children's expectations and perspectives. International Workshop on Intelligent Virtual Agents, 407-419. Springer, Berlin, Heidelberg. https://doi.org/10.1007/11821830_33

[59] Lynne Hall, Susan Jones, Ana Paiva, and Ruth Aylett. 2009. FearNot! providing children with strategies to cope with bullying. In Proceedings of the 8th International Conference on Interaction Design and Children (IDC '09). Association for Computing Machinery, New York, NY, USA, 276-277. https: //doi.org/10.1145/1551788.1551854

[60] Tian Han, Jincheng Zhang, Zhu Zhang, Guobing Sun, Liang Ye, Hany Ferdinando, Esko Alasaarela, Tapio Seppänen, Xiaoyang Yu, and Shuchang Yang. 2018. Emotion Recognition and School Violence Detection from Children Speech. EURASIP Journal on Wireless Communications \& Networking 2018 (1): 1. https://doi.org/10.1186/s13638-018-1253-8

[61] Hartati, S., Safitri, D., Marini, A. and Wahyudi, A., 2020. Bullying Behavior in Early Childhood: Study at Early Childhood Education Institution in East Jakarta in Indonesia. Journal of Talent Development and Excellence, 12(1), pp.55-63.

[62] Anne Helgeland, and Ingrid Lund. 2017. Children's Voices on Bullying in Kindergarten. Early Childhood Education Journal 45 (1): 133-41. https://doi.org/10. 1007/s10643-016-0784-z

[63] Henkel, Z. and Bethel, C.L., 2017, March. A robot forensic interviewer: The bad, the good, and the undiscovered. In Proceedings of the Companion of the 2017 ACM/IEEE International Conference on Human-Robot Interaction (pp. 10-20).

[64] Honjo, M., Hasegawa, T., Hasegawa, T., Mishima, K., Suda, T. and Yoshida, T., 2011, October. A framework to identify relationships among students in school bullying using digital communication media. In 2011 IEEE Third International Conference on Privacy, Security, Risk and Trust and 2011 IEEE Third International Conference on Social Computing (pp. 1474-1479). IEEE.

[65] Horner, S., Asher, Y. and Fireman, G.D., 2015. The impact and response to electronic bullying and traditional bullying among adolescents. Computers in human behavior, 49, pp.288-295.

[66] Yulin Hswen, Lauren Rubenzahl, and David S. Bickham. 2014. Feasibility of an online and mobile videogame curriculum for teaching children safe and healthy cellphone and Internet behaviors." GAMES FOR HEALTH: Research, Development, and Clinical Applications 3.4: 252-259. https://doi.org/10.1089/ g4h.2013.0074

[67] Huang, Y.Y. and Chou, C., 2010. An analysis of multiple factors of cyberbullying among junior high school students in Taiwan. Computers in Human Behavior, 26(6), pp.1581-1590

[68] Qianjia Huang, Vivek Kumar Singh, and Pradeep Kumar Atrey. 2014. Cyber Bullying Detection Using Social and Textual Analysis. Proceedings of the 3rd International Workshop on Socially-Aware Multimedia (SAM '14). Association for Computing Machinery, New York, NY, USA, 3-6. https://doi.org/10.1145/ 2661126.2661133

[69] Huang, C.L., Zhang, S. and Yang, S.C., 2020. How students react to different cyberbullying events: Past experience, judgment, perceived seriousness, helping behavior and the effect of online disinhibition. Computers in Human Behavior, p.106338.

[70] Ada Johansson, Anne Huhtamäki, Miia Sainio, Anne Kaljonen, Michel Boivin and Christina Salmivalli. 2020. "Heritability of Bullying and Victimization in Children and Adolescents: Moderation by the KiVa Antibullying Program. Journal of Clinical Child and Adolescent Psychology. https://doi.org/10.1080/15374416. 2020.1731820

[71] Katja Joronen, Anne Konu, Sally H. Rankin \& Päivi Åstedt-Kurki. 2012. An evaluation of a drama program to enhance social relationships and anti-bullying at elementary school: a controlled study. Health Promotion International, 27(1), 5-14. https://doi.org/10.1093/heapro/dar012 
[72] Jaana Juvonen and Elisheva F. Gross. 2008. Extending the School Grounds? Bullying Experiences in Cyberspace. The Journal of School Health 78 (9): 496-505. https://doi.org/10.1111/j.1746-1561.2008.00335.x

[73] Tessa M. L. Kaufman, Gijs Huitsing and René Veenstra. 2020. Refining Victims' Self-Reports on Bullying: Assessing Frequency, Intensity, Power Imbalance, and Goal-Directedness. Social Development 29 (2): 375-390. https://doi.org/10.1111/ sode. 12441

[74] Soyeon Kim, Scott R. Colwell, Anna Kata, Michael H. Boyle, and Katholiki Georgiades. 2018. Cyberbullying Victimization and Adolescent Mental Health Evidence of Differential Effects by Sex and Mental Health Problem Type. Journal of Youth and Adolescence 47 (3): 661-672. https://doi.org/10.1007/s10964-017 0678-4

[75] Johnny Kim, Sara Smock Jordan, Cynthia Franklin \& Adam Froerer. 2019. Is solution-focused brief therapy evidence-based? An update 10 years later. Families in Society: The Journal of Contemporary Social Services, 100, 1-12.

[76] Kokkinos, C.M., Antoniadou, N., Dalara, E., Koufogazou, A. and Papatziki, A., 2013. Cyber-bullying, personality and coping among pre-adolescents. International Journal of Cyber Behavior, Psychology and Learning (IJCBPL), 3(4) pp.55-69.

[77] Svjetlana Kolić-Vehovec, Sanja Smojver-Ažić, Tamara Martinac Dorčić, Barbara Rončević Zubković. 2020. Evaluation of Serious Game for Changing Students' Behaviour in Bullying Situation. Journal of Computer Assisted Learning 36 (3): 323-334. https://doi.org/10.1111/jcal.12402

[78] April Kontostathis, Kelly Reynolds, Andy Garron \& Lynne Edwards. 2013. Detecting cyberbullying: query terms and techniques. Proceedings of the 5th annual acm web science conference, 195-204. https://doi.org/10.1145/2464464.2464499

[79] Richard E. Kopelman, David J. Prottas, David W. Falk. 2010. "Construct Validation of a Theory X/Y Behavior Scale." Leadership and Organization Development Journal 31 (2): 120-135. https://doi.org/10.1108/01437731011024385

[80] Kowalski, R.M., Giumetti, G.W., Schroeder, A.N. and Lattanner, M.R., 2014. Bullying in the digital age: A critical review and meta-analysis of cyberbullying research among youth. Psychological bulletin, 140(4), p.1073.

[81] Simone Kriglstein, Fabian Hengstberger, Florian Fribert, Katharina Stiehl, Beate Schrank, Alexander Pfeiffer, Thomas Wernbacher, Günter Wallner. 2020. Be a Buddy not a Bully-Two Educational Games to Help Prevent Bullying in Schools. In Extended Abstracts of the 2020 Annual Symposium on Computer-Human Interaction in Play (pp. 287-291). https://doi.org/10.1145/3383668.3419914

[82] Violaine Kubiszewski, Roger Fontaine Catherine Potard and Laurent Auzoult. 2015. Does Cyberbullying Overlap with School Bullying when Taking Modality of Involvement into Account? Computers in Human Behavior 43: 49-57. https //doi.org/10.1016/j.chb.2014.10.049

[83] Antti Kärnä, Marinus Voeten, Todd D. Little, Elisa Poskiparta, Anne Kaljonen, and Christina Salmivalli. 2011. A Large-Scale Evaluation of the KiVa Antibullying Program: Grades 4-6." Child Development 82, no. 1 (January 2011): 311-30. https://doi.org/10.1111/j.1467-8624.2010.01557.x

[84] Laferriere, J. and McCreery, M., 2017, October. Examining the Efficacy of a Bullying Prevention Video Game: An Intervention for Pre-Service Teachers. In European Conference on Games Based Learning (pp. 952-954). Academic Conferences International Limited.

[85] Lapidot-Lefler, N. and Dolev-Cohen, M., 2015. Comparing cyberbullying and school bullying among school students: Prevalence, gender, and grade level differences. Social psychology of education, 18(1), pp.1-16.

[86] Law, D.M., Shapka, J.D., Hymel, S., Olson, B.F. and Waterhouse, T., 2012. The changing face of bullying: An empirical comparison between traditional and internet bullying and victimization. Computers in Human Behavior, 28(1), pp.226232 .

[87] Levine, E. and Tamburrino, M., 2014. Bullying among young children: Strategies for prevention. Early childhood education journal, 42(4), pp.271-278.

[88] Ziyi Li, Junpei Kawamoto, Yaokai Feng \& Kouichi Sakurai. 2016. Cyberbullying detection using parent-child relationship between comments. Proceedings of the 18th International Conference on Information Integration and Web-based Applications and Services, 325-334. https://doi.org/10.1145/3011141.3011182

[89] Henry Lieberman, Karthik Dinakar, and Birago Jones. 2013. Crowdsourced ethics with personalized story matching. CHI'13 Extended Abstracts on Human Factors in Computing Systems, 709-714. https://doi.org/10.1145/2468356.2468481

[90] Raquel Lozano-Blasco, Alejandra Cortés-Pascual and Maria Pilar LatorreMartínez. 2020. Being a Cybervictim and a Cyberbully - the Duality of Cyberbullying: A Meta-Analysis."Computers in Human Behavior 111. https://doi. org/10.1016/j.chb.2020.106444

[91] Jamie Macbeth, Hanna Adeyema, Henry Lieberman \& Christopher Fry. 2013 Script-based story matching for cyberbullying prevention. CHI'13 Extended Abstracts on Human Factors in Computing Systems, 901-906. https://doi.org/10. $1145 / 2468356.2468517$

[92] Juan F. Mancilla-Caceres, Eyal Amir, and Dorothy Espelage. 2013. Adaptive game for reducing aggressive behavior. In Proceedings of the companion publication of the 2013 international conference on Intelligent user interfaces companion (IUI '13 Companion). Association for Computing Machinery, New York, NY, USA, 21-24. https://doi.org/10.1145/2451176.2451183
[93] Mancilla-Caceres, J.F., Espelage, D. and Amir, E., 2014. Emotions in social computer games: Relations with bullying, aggression, and school belonging. International Journal of Gaming and Computer-Mediated Simulations (IJGCMS), 6(3), pp.50-67.

[94] Nick Mavroudis and Pagona Bournelli. 2016. The role of drama in education in counteracting bullying in schools. Cogent education 3.1: 1233843. https: //doi.org/10.1080/2331186X.2016.1233843

[95] Brenna McNally, Priya Kumar, Chelsea Hordatt, Matthew Louis Mauriello, Shalmali Naik, Leyla Norooz, Alazandra Shorter, Evan Golub, and Allison Druin. 2018. Co-designing Mobile Online Safety Applications with Children. In Proceedings of the $2018 \mathrm{CHI}$ Conference on Human Factors in Computing Systems (CHI '18). Association for Computing Machinery, New York, NY, USA, Paper 523, 1-9. https://doi.org/10.1145/3173574.3174097

[96] Mehari, K.R., Farrell, A.D. and Le, A.T.H., 2014. Cyberbullying among adolescents: Measures in search of a construct. Psychology of Violence, 4(4), p.399.

[97] Menard, S. and Grotpeter, J.K., 2014. Evaluation of bully-proofing your school as an elementary school antibullying intervention. Journal of School Violence, 13(2), pp.188-209.

[98] Midthassel, U.V., Bru, E. and Idsoe, T., 2008. Is the sustainability of reduction in bullying related to follow-up procedures?. Educational Psychology, 28(1), pp.83-95.

[99] Migliaccio, T. and Raskauskas, J., 2013. Small-scale bullying prevention discussion video for classrooms: A preliminary evaluation. Children \& Schools, 35(2), pp.71-81.

[100] Faye Mishna, Michael Saini and Steven Solomon. 2009. "Ongoing and Online: Children and Youth's Perceptions of Cyber Bullying." Children and Youth Services Review 31 (12): 1222-1228. https://doi.org/10.1016/j.childyouth.2009.05.004

[101] Mohyla, J. and Slee, P.T., 2012, July. THE PEACE Pack \& SITE Software: Interventions to reduce bullying in Australian schools. In 2012 7th International Conference on Computer Science \& Education (ICCSE) (pp. 457-461). IEEE.

[102] Mudraka, G. and Semwalb, S.K., 2015. Modeling aggression and bullying: a complex systems approach. Annual Review Of Cybertherapy And Telemedicine 2015, p.187.

[103] George Mudrak and Sudhanshu Kumar Semwal. 2016. Group Aggression and Bullying through Complex Systems Agent Based Modeling. Annual Review of CyberTherapy and Telemedicine 14: 189-193.

[104] Neo, H.F., Teo, C.C. and Boon, J.L.H., 2018, October. Mobile Edutainment Learning Approach: \# StopBully. In Proceedings of the 2nd International Conference on Digital Technology in Education (pp. 6-10).

[105] Iolie Nicolaidou \& Agnes Venizelou. 2020. Improving children's E-safety skills through an interactive learning environment: A quasi-experimental study. Multimodal Technologies and Interaction, 4(2) https://doi.org/10.3390/mti4020010

[106] Nikiforos, S., Tzanavaris, S. and Kermanidis, K.L., Virtual learning communities (VLCs) rethinking: influence on behavior modification-bullying detection through machine learning and natural language processing. Journal of Computers in Education 2020

[107] Nocentini, A., Zambuto, V. and Menesini, E., 2015. Anti-bullying programs and Information and Communication Technologies (ICTs): A systematic review. Aggression and Violent Behavior, 23, pp.52-60.

[108] Dan Olweus. 1994. Bullying at School. In: Huesmann L.R. (eds) Aggressive Behavior. The Plenum Series in Social/Clinical Psychology. Springer, Boston, MA. https://doi.org/10.1007/978-1-4757-9116-7_5

[109] Dan Olweus. 2012. Cyberbullying: An Overrated Phenomenon? European Journal of Developmental Psychology 9 (5), 520-538. https://doi.org/10.1080/ 17405629.2012 .682358

[110] Olweus, D., 2013. School bullying: Development and some important challenges. Annual review of clinical psychology, 9, pp.751-780.

[111] Osumi, T., Osawa, H. and Imai, M., 2016. Simulation of bullying and conforming in a class based on socion theory. Electronics and Communications in Japan, 99(7), pp.12-24.

[112] Palladino, B.E., Nocentini, A. and Menesini, E., 2016. Evidence-based intervention against bullying and cyberbullying: Evaluation of the NoTrap! program in two independent trials. Aggressive behavior, 42(2), pp.194-206.

[113] Samiullah Paracha, Lynne Hall, Kathy Clawson, Nicole Mitsche. 2020. Design, Development, and Usability of a Virtual Environment on Moral, Social, and Emotional Leaning. International Journal of Virtual and Personal Learning Environments 10 (2): 50-65. https://doi.org/10.4018/IJVPLE.2020070104

[114] Cátia Raminhos, Ana Paula Cláudio, Maria Beatriz Carmo, Susana Carvalhosa, Maria de Jesus Candeias, and Augusta Gaspar. 2015. A serious game-based solution to prevent bullying. In Proceedings of the 13th International Conference on Advances in Mobile Computing and Multimedia (MoMM 2015). Association for Computing Machinery, New York, NY, USA, 63-72. https://doi.org/10.1145/ 2837126.2837135

[115] Resett, S. and Gámez-Guadix, M., 2017. Traditional bullying and cyberbullying: Differences in emotional problems, and personality. Are cyberbullies more Machiavellians?. Journal of Adolescence, 61, pp.113-116.

[116] Roberts Jr, W. B., \& Morotti, A. A. (2000). The bully as victim: Understanding bully behaviors to increase the effectiveness of interventions in the bully-victim 
dyad. Professional School Counseling, 4(2), 148.

[117] Alice Rubin-Vaughan, Debra Pepler, Steven Brown and Wendy Craig. 2011 Quest for the Golden Rule: An Effective Social Skills Promotion and Bullying Prevention Program." Computers and Education 56 (1): 166-175. https://doi.org/ 10.1016/j.compedu.2010.08.009

[118] Carolina Beniamina Rutta, Gianluca Schiavo, Massimo Zancanaro, and Elisa Rubegni. 2019. Comic-based Digital Storytelling with Primary School Children. Proceedings of the 18th ACM International Conference on Interaction Design and Children (IDC '19). Association for Computing Machinery, New York, NY, USA, 508-513. https://doi.org/10.1145/3311927.3325331

[119] Carolina Beniamina Rutta, Gianluca Schiavo, Massimo Zancanaro, and Elisa Rubegni. 2020. Collaborative comic-based digital storytelling with primary school children. Proceedings of the Interaction Design and Children Conference (IDC '20). Association for Computing Machinery, New York, NY, USA, 426-437. https://doi.org 10.1145/3392063.3394433

[120] Mustafa Şahin. 2012. The Relationship between the cyberbully ing/cybervictmization and Loneliness among Adolescents. Children and Youth Services Review 34 (4): 834-837. https://doi.org/10.1016/j.childyouth.2012.01.010

[121] Salcedo, L.P. and Contreras, A.R., 2011, May. Group formation for minimizing bullying probability. A proposal based on genetic algorithms. In International Work-Conference on the Interplay Between Natural and Artificial Computation (pp. 148-156). Springer, Berlin, Heidelberg.

[122] Christina Salmivalli, Elisa Poskiparta, Annarilla Ahtola, and Anne Haataja. 2013 The Implementation and Effectiveness of the KiVa Antibullying Program in Finland. European Psychologist, School Success, 18, no. 2, 79-88. https://doi org/10.1027/1016-9040/a000140

[123] Ana Dolores Vargas Sánchez and Luis Eduardo Veloza Chamucero. 2017. Ed ucation in Conflict Resolution using ICT: A Case Study in Colombia. Journal of Cases on Information Technology 19 (2): 29-43. https://doi.org/10.4018/JCIT. 2017040103

[124] Olivia Saracho. 2017. Bullying Prevention Strategies in Early Childhood Education. Early Childhood Education Journal 45 (4): 453-60. https://doi.org/10.1007/ s10643-016-0793-y

[125] Carmen R. Sedano, Edson L. Ursini and Paulo S. Martins. 2017. A BullyingSeverity Identifier Framework Based on Machine Learning and Fuzzy Logic Lecture Notes in Computer Science (Including Subseries Lecture Notes in Artificial Intelligence and Lecture Notes in Bioinformatics). Vol. 10245 LNAI. https://doi.org/10.1007/978-3-319-59063-9_28

[126] Shaw, T., Campbell, M.A., Eastham, J., Runions, K.C., Salmivalli, C. and Cross, D., 2019. Telling an adult at school about bullying: Subsequent victimization and internalizing problems. Journal of Child and Family Studies, 28(9), pp.2594-2605

[127] Shiakou, M. and Piki, L., 2020. Assessing the role of drama on children's understanding of bullying. International Journal of School \& Educational Psychology, 8(1), pp.11-20.

[128] Yasin N. Silva, Christopher Rich, Jaime Chon \& Lisa M. Tsosie. 2016. Bully Blocker: An app to identify cyberbullying in facebook. In 2016 IEEE/ACM International Conference on Advances in Social Networks Analysis and Mining (ASONAM), 1401-1405. IEEE. https://doi.org/10.1109/ASONAM.2016.7752430

[129] Phillip T. Slee and Jury Mohyla. 2007. The PEACE Pack: an evaluation of interventions to reduce bullying in four Australian primary schools, Educational Research, 49:2, 103-114, https://doi.org/10.1080/00131880701369610

[130] Slonje, R., Smith, P.K. and Frisén, A., 2013. The nature of cyberbullying, and strategies for prevention. Computers in human behavior, 29(1), pp.26-32.

[131] Jiyeon Song and Insoo Oh. 2018. Factors Influencing Bystanders' Behavioral Reactions in Cyberbullying Situations. Computers in Human Behavior 78: 273282. https://doi.org/10.1016/j.chb.2017.10.008

[132] Michael Sloenthorn Speek and Maarten Van Mechelen. 2018. Storytelling shapes: a toolkit to enable children to express their needs and wishes. In Proceedings of the 17th ACM Conference on Interaction Design and Children (IDC '18) Association for Computing Machinery, New York, NY, USA, 619-624. https: //doi.org/10.1145/3202185.3210785

[133] Kalliopi-Evangelia Stavroulia, A. Ruiz-Harisiou, Elena Manouchou, K. Georgiou, F. Sella, and Andreas Lanitis. 2016. A 3D Virtual Environment for Training Teachers to Identify Bullying. https://doi.org/10.1109/MELCON.2016.7495417

[134] Claire Sutherland, Lynne Coventry, and Elizabeth Sillence. 2014. Using animated scenarios to explore severity of cyberbullying and reporting readiness. Proceedings of the 26th Australian Computer-Human Interaction Conference on Designing Futures: the Future of Design, 448-451. https://doi.org/10.1145/ 2686612.2686683

[135] Nargess Tahmasbi, and Elham Rastegari. 2018. A socio-contextual approach in automated detection of public cyberbullying on Twitter. ACM Transactions on Social Computing 1.4: 1-22. https://doi.org/10.1145/3290838

[136] James M. Thomas and Melissa E. DeRosier. 2010. Toward effective game-based social skills tutoring for children: an evaluation of a social adventure game. In Proceedings of the Fifth International Conference on the Foundations of Digital Games (FDG '10). Association for Computing Machinery, New York, NY, USA 217-223. https://doi.org/10.1145/1822348.1822377
[137] Jane Timmons-Mitchell, Deborah A. Levesque, Leon A. Harris III, Daniel J. Flannery, and Tatiana Falcone. 2016. Pilot Test of StandUp, an Online SchoolBased Bullying Prevention Program. Children \& Schools 38 (2): 71-79. https: //doi.org/10.1093/cs/cdw010

[138] Min-Kun Tsai, Shian-Shyong Tseng and Jui-Feng Weng. 2011. A Pilot Study of Interactive Storytelling for Bullying Prevention Education. Lecture Notes in Computer Science (Including Subseries Lecture Notes in Artificial Intelligence and Lecture Notes in Bioinformatics). Vol. 6872 LNCS. https://doi.org/10.1007/ 978-3-642-23456-9_89

[139] Michael Tsang, Vadim Korolik, Stefan Scherer and Maja J. Mataric. 2018. Comparing Models for Gesture Recognition of Children's Bullying Behaviors. https://doi.org/10.1109/ACII.2017.8273591

[140] Ttofi, M.M. and Farrington, D.P., 2011. Effectiveness of school-based programs to reduce bullying: A systematic and meta-analytic review. Journal of Experimental Criminology, 7(1), pp.27-56.

[141] Janneke Van Der Zwaan, Virginia Dignum, Catholijn Jonker. 2010. Simulating peer support for victims of cyberbullying. In BNAIC 2010: 22rd Benelux Conference on Artificial Intelligence, Luxembourg, 25-26 October 2010.

[142] Maarten Van Mechelen, Gavin Sim, Bieke Zaman, Peggy Gregory, Karin Slegers, and Matthew Horton. 2014. Applying the CHECk tool to participatory design sessions with children. In Proceedings of the 2014 conference on Interaction design and children (IDC '14). Association for Computing Machinery, New York, NY, USA, 253-256. https://doi.org/10.1145/2593968.2610465

[143] Maarten Van Mechelen, Ann Laenen, Bieke Zaman, Bert Willems, Vero Vanden Abeele. 2019. Collaborative Design Thinking (CoDeT): A co-design approach for high child-to-adult ratios. In International Journal of Human-Computer Studies, Volume 130, 179-195. https://doi.org/10.1016/j.ijhcs.2019.06.013

[144] Natalie Vannini, Sibylle Enz, Maria Sapouna, Dieter Wolke, Scott Watson, Sarah Woods, Kerstin Dautenhahn, Lynne Hall, Ana Paiva, Elizabeth André, Ruth Aylett \& Wolfgang Schneider. 2011. "FearNot!": a computer-based anti-bullyingprogramme designed to foster peer intervention. European journal of psychology of education, 26(1), 21-44. https://doi.org/10.1007/s10212-010-0035-4

[145] Wassanasompong, W. and tussaworn, S., 2019, October. The Effects of Health Education Instruction Using Problem-based Learning on Knowledge and Critical Thinking about Cyberbullying of Junior High School Students. In Proceedings of the 2019 The 3rd International Conference on Digital Technology in Education (pp. 68-72).

[146] Scott E.J. Watson, Natalie Vannini, Sarah Woods, Kerstin Dautenhah, Maria Sapouna, Sibylle Enz, Wolfgang Schneider, Dieter Wolke, Lynne Hall, Ana Paiva, Elizabeth André \&Ruth Aylett. 2010. Inter-cultural differences in response to a computer-based anti-bullying intervention. Educational Research, 52(1), 61-80. https://doi.org/10.1080/00131881003588261

[147] Anne Williford and Kathryn J. DePaolis. 2019. Validation of a Cyber Bullying and Victimization Measure among Elementary School-Aged Children. Child and Adolescent Social Work Journal 36 (5): 557-570. https://doi.org/10.1007/s10560018-0583-z

[148] Vreeman, R.C. and Carroll, A.E., 2007. A systematic review of school-based interventions to prevent bullying. Archives of pediatrics \& adolescent medicine, 161(1), pp.78-88

[149] Jun-Ming Xu, Xiaojin Zhu, and Amy Bellmore. 2012. Fast learning for sentiment analysis on bullying. In Proceedings of the First International Workshop on Issues of Sentiment Discovery and Opinion Mining (WISDOM '12). Association for Computing Machinery, New York, NY, USA, Article 10, 1-6. https://doi.org/ $10.1145 / 2346676.2346686$

[150] Yang, A. and Salmivalli, C., 2015. Effectiveness of the KiVa antibullying programme on bully-victims, bullies and victims. Educational research, 57(1), pp.8090

[151] Liang Ye, Peng Wang, Le Wang, Hany Ferdinando, Tapio Seppänen and Esko Alasaarela. 2018. A Combined Motion-Audio School Bullying Detection Algorithm. International Journal of Pattern Recognition and Artificial Intelligence 32 (12). https://doi.org/10.1142/S0218001418500465

[152] Liang Ye, Jifu Shi, Hany Ferdinando, Tapio Seppänen and Esko Alasaarela. 2020. School Violence Detection Based on Multi-Sensor Fusion and Improved ReliefF Algorithms. Lecture Notes of the Institute for Computer Sciences, SocialInformatics and Telecommunications Engineering, LNICST. Vol. 287. https: //doi.org/10.1007/978-3-030-22971-9 22

[153] Yokoo, M., Wakuta, M. and Shimizu, E., 2018. Educational effectiveness of a video lesson for bullying prevention. Children \& Schools, 40(2), pp.71-79.

[154] Eun Young Oh, Donggil Song and Hyeonmi Hong. 2020. Interactive computing technology in anti-bullying education: The effects of conversation-bot's role on K-12 students' attitude change toward bullying problems. Journal of Educational Computing Research 58.1, 200-219. https://doi.org/10.1177/0735633119839177

[155] Sue Young. 2016. Ratkaisukeskeinen lähetymistapa koulukiusaamiseen. In Peter de Jong and Insoo Kim Berg. 2016 Ratkaisukeskeisen lyhytterapian oppikirja. Helsinki: Lyhytterapiainstutuutti Oy, 287-296. (Original Sue Young. Solutions for Bullying in Primary Schools. In Peter de Jong and Insoo Kim Berg. 2008. Interviewing for solutions (3rd ed.). Belmont, CA: Thomson Higher Education, 308-318.) 


\section{APPENDICES}

Appendix A lists the included studies, the countries in which the studies were conducted, the main methods for data collection used for studying bullying, the age categories of children addressed in the studies and the main foci of the solutions proposed for tackling bullying.

\begin{tabular}{|c|c|c|c|c|}
\hline \multicolumn{2}{|c|}{ ReferenceCountry } & \multirow{2}{*}{$\begin{array}{l}\text { Methods } \\
\text { Interviews }\end{array}$} & \multirow{2}{*}{$\begin{array}{l}\text { Age category } \\
\text { Adolescent (ages 13-19) }\end{array}$} & \multirow{2}{*}{$\begin{array}{l}\text { Solution } \\
-\end{array}$} \\
\hline [1] & USA & & & \\
\hline [2] & NA & Reviewing other studies & Wider age group & - \\
\hline [3] & NA & NA & Primary school-aged child (ages 6-12 years) & Technology \\
\hline$[4]$ & USA & Questionnaire & Over 18 year olds & - \\
\hline$[5]$ & USA & Creative/reflection based methods & Adolescent (ages 13-19) & Design \\
\hline [7] & NA & Creative/reflection based methods & Primary school-aged child (ages 6-12 years) & Design \\
\hline [8] & USA & Creative/reflection based methods & Primary school-aged child (ages 6-12 years) & Design, technology \\
\hline [9] & USA & Interviews & Primary school-aged child (ages 6-12 years) & - \\
\hline [10] & Sweden & Questionnaire & Adolescent (ages 13-19) & - \\
\hline [11] & Spain & Questionnaire & Adolescent (ages 13-19) & - \\
\hline [12] & Canada & Questionnaire & Wider age group & - \\
\hline [13] & NA & Technology based methods & Primary school-aged child (ages 6-12 years) & Technology \\
\hline$[14]$ & Canada & Questionnaire & Adolescent (ages 13-19) & - \\
\hline [15] & NA & Technology based methods & Primary school-aged child (ages 6-12 years) & Technology \\
\hline$[16]$ & USA & Creative/reflection based methods & Wider age group & Design \\
\hline [17] & NA & Reviewing other studies & Age not mentioned & - \\
\hline [18] & NA & NA & Wider age group & Technology \\
\hline [19] & USA & Questionnaire & Adolescent (ages 13-19) & - \\
\hline$[20]$ & Spain & Questionnaire & Over 18 year olds & Technology \\
\hline [21] & NA & Reviewing other studies & Wider age group & Technology \\
\hline$[22]$ & Spain & Questionnaire & Adolescent (ages 13-19) & Technology \\
\hline [23] & Australia & Questionnaire & Wider age group & - \\
\hline$[25]$ & Spain & Questionnaire & Adolescent (ages 13-19) & - \\
\hline$[26]$ & NA & Reviewing other studies & Wider age group & - \\
\hline [27] & $\begin{array}{l}\text { China, } \\
\text { Taiwan, } \\
\text { Hong Kong, } \\
\text { and Macau }\end{array}$ & Reviewing other studies & Wider age group & - \\
\hline$[28]$ & Malaysia & Interviews & Adolescent (ages 13-19) & - \\
\hline [29] & NA & Technology based methods & Wider age group & Technology \\
\hline$[30]$ & NA & NA & Age not mentioned & - \\
\hline [31] & Taiwan & Questionnaire & Primary school-aged child (ages 6-12 years) & - \\
\hline$[32]$ & Italy & Questionnaire & Primary school-aged child (ages 6-12 years) & - \\
\hline [33] & NA & Reviewing other studies & Adolescent (ages 13-19) & - \\
\hline [34] & Portugal & Questionnaire & Adolescent (ages 13-19) & - \\
\hline$[35]$ & Canada & Technology based methods & Other & Technology \\
\hline [36] & Ireland & Reviewing other studies & Adolescent (ages 13-19) & - \\
\hline [38] & NA & Creative/reflection based methods & Primary school-aged child (ages 6-12 years) & Design \\
\hline [39] & NA & Questionnaire & Other & - \\
\hline$[40]$ & Belgium & Questionnaire & Adolescent (ages 13-19) & Technology \\
\hline [41] & NA & Technology based methods & Age not mentioned & Technology \\
\hline [42] & China & Questionnaire & Adolescent (ages 13-19) & - \\
\hline [43] & USA & Other & Age not mentioned & - \\
\hline$[44]$ & USA & Technology based methods & Primary school-aged child (ages 6-12 years) & Technology \\
\hline [45] & $\begin{array}{l}\text { UK and } \\
\text { Germany }\end{array}$ & Other & Primary school-aged child (ages 6-12 years) & Technology \\
\hline [46] & Denmark & Interviews & Primary school-aged child (ages 6-12 years) & Design, technology \\
\hline$[47]$ & NA & Reviewing other studies & Age not mentioned & - \\
\hline [48] & Finland & NA & Wider age group & Technology \\
\hline [49] & NA & Reviewing other studies & Age not mentioned & Technology \\
\hline$[50]$ & NA & Questionnaire & Wider age group & Technology \\
\hline
\end{tabular}




\begin{tabular}{|c|c|c|c|c|}
\hline \multicolumn{2}{|c|}{ ReferenceCountry } & \multirow{2}{*}{$\begin{array}{l}\text { Methods } \\
\text { Technology based methods }\end{array}$} & \multirow{2}{*}{$\begin{array}{l}\text { Age category } \\
\text { Age not mentioned }\end{array}$} & \multirow{2}{*}{$\begin{array}{l}\text { Solution } \\
\text { Technology }\end{array}$} \\
\hline$[53]$ & Finland & & & \\
\hline$[55]$ & NA & Interviews & Adolescent (ages 13-19) & - \\
\hline$[56]$ & Australia & Reviewing other studies & Age not mentioned & - \\
\hline$[57]$ & $\begin{array}{l}\text { UK and } \\
\text { Germany }\end{array}$ & Creative/reflection based methods & Primary school-aged child (ages 6-12 years) & Design \\
\hline$[58]$ & UK & Interviews & Primary school-aged child (ages 6-12 years) & Design, technology \\
\hline$[59]$ & $\begin{array}{l}\text { UK and } \\
\text { Germany }\end{array}$ & Questionnaire & Primary school-aged child (ages 6-12 years) & Technology \\
\hline$[60]$ & Finland & Technology based methods & Primary school-aged child (ages 6-12 years) & Technology \\
\hline$[61]$ & Indonesia & Questionnaire & Preschooler (ages $2-5$ years) & - \\
\hline$[62]$ & Norway & Interviews & Preschooler (ages 2-5 years) & - \\
\hline$[63]$ & NA & Reviewing other studies & Primary school-aged child (ages 6-12 years) & Technology \\
\hline$[64]$ & NA & Technology based methods & Age not mentioned & Technology \\
\hline$[65]$ & USA & Other & Adolescent (ages 13-19) & - \\
\hline$[66]$ & USA & Other & Primary school-aged child (ages 6-12 years) & Technology \\
\hline$[67]$ & Taiwan & Questionnaire & Adolescent (ages 13-19) & - \\
\hline$[68]$ & NA & Technology based methods & Wider age group & Technology \\
\hline$[69]$ & China & Questionnaire & Adolescent (ages 13-19) & - \\
\hline [70] & Finland & Questionnaire & Wider age group & - \\
\hline [71] & Finland & Questionnaire & Primary school-aged child (ages 6-12 years) & - \\
\hline$[72]$ & USA & Questionnaire & Adolescent (ages 13-19) & - \\
\hline$[73]$ & Netherlands & Questionnaire & Primary school-aged child (ages 6-12 years) & - \\
\hline$[74]$ & Canada & Questionnaire & Adolescent (ages 13-19) & - \\
\hline$[75]$ & South Korea & Interviews & Other & - \\
\hline$[76]$ & Greece & Questionnaire & Primary school-aged child (ages 6-12 years) & - \\
\hline$[77]$ & $\begin{array}{l}\text { Spain, } \\
\text { Malta, UK } \\
\text { and Ireland }\end{array}$ & Questionnaire & Adolescent (ages 13-19) & Technology \\
\hline$[78]$ & NA & Technology based methods & Wider age group & Technology \\
\hline$[80]$ & NA & Reviewing other studies & Primary school-aged child (ages 6-12 years) & - \\
\hline$[81]$ & Austria & Other & Primary school-aged child (ages 6-12 years) & Technology \\
\hline$[82]$ & France & Interviews & Wider age group & - \\
\hline$[83]$ & Finland & Questionnaire & Primary school-aged child (ages 6-12 years) & - \\
\hline$[84]$ & NA & Interviews & Other & Technology \\
\hline$[85]$ & Israel & Questionnaire & Adolescent (ages 13-19) & - \\
\hline$[86]$ & Canada & Questionnaire & Adolescent (ages 13-19) & - \\
\hline$[87]$ & NA & Reviewing other studies & Primary school-aged child (ages 6-12 years) & - \\
\hline$[88]$ & NA & Technology based methods & Age not mentioned & Technology \\
\hline [89] & USA & Other & Over 18 year olds & Technology \\
\hline$[90]$ & NA & Reviewing other studies & Adolescent (ages 13-19) & - \\
\hline$[91]$ & NA & Technology based methods & Age not mentioned & Technology \\
\hline$[92]$ & NA & Technology based methods & Primary school-aged child (ages 6-12 years) & Technology \\
\hline [93] & NA & Questionnaire & Primary school-aged child (ages 6-12 years) & Technology \\
\hline$[94]$ & Greece & Reviewing other studies & Primary school-aged child (ages 6-12 years) & - \\
\hline$[95]$ & USA & Creative/reflection based methods & Primary school-aged child (ages 6-12 years) & Design, technology \\
\hline$[96]$ & NA & Reviewing other studies & Adolescent (ages 13-19) & - \\
\hline$[97]$ & USA & Questionnaire & Primary school-aged child (ages 6-12 years) & - \\
\hline$[98]$ & Norway & Questionnaire & Wider age group & - \\
\hline [99] & NA & Questionnaire & Primary school-aged child (ages 6-12 years) & - \\
\hline$[100]$ & Canada & Interviews & Primary school-aged child (ages 6-12 years) & - \\
\hline$[101]$ & Australia & NA & Primary school-aged child (ages 6-12 years) & - \\
\hline$[102]$ & NA & Technology based methods & Age not mentioned & Technology \\
\hline$[103]$ & NA & Technology based methods & Age not mentioned & Technology \\
\hline$[104]$ & Malaysia & Questionnaire & Over 18 year olds & Technology \\
\hline$[105]$ & NA & Other & Primary school-aged child (ages6-12 years) & Technology \\
\hline
\end{tabular}




\begin{tabular}{|c|c|c|c|c|}
\hline \multicolumn{2}{|c|}{ ReferenceCountry } & \multirow{2}{*}{$\begin{array}{l}\text { Methods } \\
\text { Technology based methods }\end{array}$} & \multirow{2}{*}{$\begin{array}{l}\text { Age category } \\
\text { Wider age group }\end{array}$} & \multirow{2}{*}{$\frac{\text { Solution }}{\text { Technology }}$} \\
\hline$[106]$ & Greece & & & \\
\hline$[107]$ & NA & Reviewing other studies & Age not mentioned & Technology \\
\hline [109] & $\begin{array}{l}\text { Norway and } \\
\text { USA }\end{array}$ & Questionnaire & Age not mentioned & - \\
\hline$[110]$ & $\begin{array}{l}\text { Norway and } \\
\text { USA }\end{array}$ & Reviewing other studies & Age not mentioned & - \\
\hline$[111]$ & Japan & Technology based methods & Primary school-aged child (ages 6-12 years) & Technology \\
\hline$[112]$ & Italy & Questionnaire & Adolescent (ages 13-19) & - \\
\hline [113] & Japan & $\widetilde{C}$ reative/reflection based methods & Primary school-aged child (ages 6-12 years) & Design, technology \\
\hline$[114]$ & Portugal & Questionnaire & Primary school-aged child (ages 6-12 years) & Technology \\
\hline$[115]$ & Argentina & Questionnaire & Adolescent (ages 13-19) & - \\
\hline$[117]$ & Canada & Questionnaire & Primary school-aged child (ages 6-12 years) & Technology \\
\hline$[118]$ & Italy & Creative/reflection based methods & Primary school-aged child (ages 6-12 years) & Design, technology \\
\hline [119] & Italy & Creative/reflection based methods & Primary school-aged child (ages 6-12 years) & Design, technology \\
\hline$[120]$ & Turkey & Questionnaire & Adolescent (ages 13-19) & - \\
\hline$[121]$ & NA & NA & Age not mentioned & Technology \\
\hline$[122]$ & Finland & Questionnaire & Primary school-aged child (ages 6-12 years) & - \\
\hline$[123]$ & Colombia & Technology based methods & Age not mentioned & Technology \\
\hline$[124]$ & NA & Reviewing other studies & Preschooler (ages $2-5$ years) & - \\
\hline$[125]$ & NA & Technology based methods & Adolescent (ages 13-19) & Technology \\
\hline$[126]$ & Australia & Interviews & Adolescent (ages 13-19) & - \\
\hline$[127]$ & Cyprus & Other & Primary school-aged child (ages 6-12 years) & - \\
\hline$[128]$ & NA & Technology based methods & Age not mentioned & Technology \\
\hline [129] & Australia & Questionnaire & Primary school-aged child (ages 6-12 years) & - \\
\hline$[130]$ & Sweden & Reviewing other studies & Adolescent (ages 13-19) & - \\
\hline$[131]$ & South Korea & Questionnaire & Adolescent (ages 13-19) & - \\
\hline$[132]$ & NA & Creative/reflection based methods & Primary school-aged child (ages 6-12 years) & Design \\
\hline [133] & NA & Questionnaire & Other & Technology \\
\hline$[134]$ & Australia & Technology based methods & Primary school-aged child (ages 6-12 years) & - \\
\hline$[135]$ & NA & Technology based methods & Age not mentioned & Technology \\
\hline$[136]$ & USA & Questionnaire & Primary school-aged child (ages 6-12 years) & Technology \\
\hline$[137]$ & USA & Interviews & Adolescent (ages 13-19) & Technology \\
\hline$[138]$ & NA & Creative/reflection based methods & Adolescent (ages 13-19) & Design, technology \\
\hline [139] & USA & Technology based methods & Wider age group & Technology \\
\hline$[140]$ & NA & Reviewing other studies & Wider age group & - \\
\hline$[141]$ & NA & NA & Age not mentioned & Technology \\
\hline$[142]$ & Belgium & Creative/reflection based methods & Primary school-aged child (ages 6-12 years) & Design \\
\hline [143] & Belgium & Creative/reflection based methods & Primary school-aged child (ages 6-12 years) & Design \\
\hline$[144]$ & $\begin{array}{l}\text { Germany } \\
\text { and UK }\end{array}$ & Questionnaire & Primary school-aged child (ages 6-12 years) & Technology \\
\hline$[145]$ & Thailand & Questionnaire & Adolescent (ages 13-19) & - \\
\hline [146] & $\begin{array}{l}\text { UK and } \\
\text { Germany }\end{array}$ & Questionnaire & Primary school-aged child (ages 6-12 years) & Technology \\
\hline$[147]$ & USA & Questionnaire & Primary school-aged child (ages 6-12 years) & - \\
\hline$[148]$ & NA & Reviewing other studies & Wider age group & - \\
\hline [149] & NA & Technology based methods & Age not mentioned & Technology \\
\hline$[150]$ & Finland & Questionnaire & Wider age group & - \\
\hline$[151]$ & Finland & Technology based methods & Age not mentioned & Technology \\
\hline$[152]$ & NA & Technology based methods & Other & Technology \\
\hline [153] & Japan & Questionnaire & Primary school-aged child (ages 6-12 years) & - \\
\hline$[154]$ & NA & NA & Primary school-aged child (ages 6-12 years) & Technology \\
\hline$[151]$ & China & Technology based methods & Preschooler (ages $2-5$ years) & Technology \\
\hline
\end{tabular}

